\title{
Un regidor madrileño instruido en leyes: la biblioteca de Francisco de Peralta
}

\author{
Ana GuerRero Mayllo
}

\section{INTRODUCCIÓN}

El descubrimiento y el consiguiente análisis de las bibliotecas y de las aficiones literarias en la España Moderna, están de enhorabuena. Son numerosos ya los trabajos publicados al respecto, especialmente enfocados hacia figuras de renombre ${ }^{1}$. Sin embargo, olvidamos a menudo que personajes de "segunda fila" ", tuvieron igual o mayor interés por la lectura que nobles, altos burócratas y eclesiásticos. Éste es el caso de las oligarquías municipales, aunque por ahora es un campo apenas explorado por la investigación. Pero conocer la cultura y el gusto por la lectura de este grupo social y de poder es esencial en tanto en cuanto puede determinar su comportamiento en el gobierno de las ciudades y cómo abordar los problemas que suscita su gestión ${ }^{3}$.

Nuestro trabajo se va a centrar en la biblioteca de un determinado miembro del regimiento madrileño, el licenciado Francisco de Peralta, y

La abundancia de títulos al respecto y los problemas de espacio, nos obligan a sintetizar tan extensa bibliografía en obras que ofrecen un estado de la cuestión: LOPEZ, F., "Estado actual de la historia del libro en España», Anales de la Universidad de Alicante, 4 (1984), págs. 11-22. Chevalier, M., Lectura y lectores en la España de los siglos Xv/ y xvil. Madrid 1976. Befger, Ph., Libros y lectura en la Valencia del Renacimiento. Valencia 1987. Martin, H. J., Livre, pouvoirs et societé a Paris XVII siécle (1598-1701). Ginebra 1969. G:L Fernández, L., Panorama social del Humanismo español (1500-1800). Madrid 1981.

2 Elliott, J. H. , y Peña J. F., Memoriales y Cartas del Conde-Duque de Olivares. Madrid 1978, I, pág. XXIII.

${ }^{3}$ Guerrero Mayllo, A., Oligarquia y gobierno municipal en la Corte de la Monarquía Hispánica. El concejo de Madrid entre 1560 y 1606. Madrid, Servicio de Investigación de la UNED, 1991. 
ello por una razón fundamental: es la mejor inventariada y, desde luego, la más voluminosa. Esto no significa, por supuesto, que los demás capitulares no mostraran interés por la lectura, aunque si hemos de atenernos a los inventarios todo parece indicar que raramente se sintieron atraidos hacia el libro. En efecto, de los 171 capitulares que desempeñan el oficio en Madrid entre los años 1560 y 1606, apenas si disponemos de un par de docenas de inventarios post-mortem y testamentos donde consten de una u otra forma las bibliotecas que poseian, siendo verdaderamente escasas las que brindan una información completa y rica, capaces de traslucir, por tanto, las inquietudes culturales del grupo social al que representan. Sirva de ejemplo el inventario de Pedro Fernández de Alarcón, donde se dice que tiene treinta y un libros «de pliego entero» de devoción, un soneto de jeroglíficos en pergamino, y quince libros de «quartilla de papel y de menos" de diferentes historias ${ }^{4}$.

Este reducido porcentaje de bibliotecas, algo inferior al que ha obtenido la profesora Fayard para los consejeros de Castilla (alrededor del 10 por 100), sorprende tanto más cuando la mayoria de los regidores y sus familias, aunque desconocian el latín ${ }^{5}$, sabían leer y escribir, teniendo algunos de ellos o sus padres estudios superiores. Entre los últimos cabe mencionar al padre de Iñigo de Cárdenas y Zapata, que estuvo siete años en el colegio de Bolonia o al de Gabriel de Alarcón, colegial en el de Santa Cruz de Valladolid ${ }^{6}$; de los primeros, se puede citar a los licenciados García Barrionuevo de Peralta, Diego de la Canal, Rodrigo Luján, Pedro Medina, Giberto de Bedoya, Diego Salas, Juan de Sosa, Juan Tejada, y al doctor Leonardo de Cos. Asimismo, resulta curioso observar cómo un pequeño número de regidores lega determinadas sumas de dinero para la formación académica de sus parientes y, sin embargo, no parecen

\footnotetext{
${ }^{4}$ Archivo Histórico de Protocolos Notoriales de Madrid (APM), Prot,, 2013, f. 286, 8 de febrero de 1613.

${ }^{5}$ Archivo de la Villa de Madrid (AVM), Libros de Acuerdos, 23 de septiembre de 1562 «...atento que la cátedra de Gramática desta villa está vaca conviene mucho que se nombre para ella persona que tenga mucha sufiçiencia y abilidad y bondad, para ello se a enbiado a publicar a Salamanca y Alcalá y otras partes y para que esto pueda mejor hazer y con más autorydad y restitud, les pareçe que por ser los más de los cavalleros deste ayuntamiento personas que no saben latín (..), se llamen de todos los monesterios desta villa, el prior y otro frayle, el que más pudiere saber desto...".

6 El padre de nuestro regidor, legó al Colegio de Bolonia, según mandaba la tradición, 300 ducados. APM, Prot. 295, f. 1353, 5 de agosto de 1584. Acerca de esta costumbre, FAYARD, J., Los miembros del Consejo de Castilla (1621-1746). Madrid 1982, pág. 490 y LARIO D., Sobre los origenes del burócrata Moderno. El Colegio de España en Bolonia durante la impermeabilización habsburguesa, 1568-1659. Bolonia 1980. En cuanto al padre de Gabriel de Alarcón, Archivo Histórico Nacional (AHN), Órdenes Militares (OO.MM), Expedientes de Santiago, 183.
} 
demostrar ningún interés por la lectura ni siquiera de obras relacionadas con el desempeño de sus funciones en el gobierno de la Monarquía, como sucede con Luis Herrera, Alonso Martínez de Cos, Francisco Zapata de Cisneros, Andrés Méndez de Jibaja o la primera esposa de Gabriel de Alarcón, quien deja a un sobrino 500 ducados para estudiar leyes en Salamanca, además de otros 200 ducados para la adquisición de libros ${ }^{7}$.

\section{EL REGIDOR DON FRANCISCO DE PERALTA}

El licenciado Francisco de Peralta accede al concejo a través de la depositaría general, oficio que, a la sazón, disfrutaban sus parientes, los Barrionuevo de Peralta, desde el año 1562, fecha en la que el rey lo había vendido por 300.000 maravedies al licenciado García Barrionuevo de Peralta "por su vida y la de un heredero» $y$, desde entonces, y a través de testaferros, habia permanecido en su poder mediante al mecanismo legal de la renuncia ${ }^{8}$. Natural de Madrid y avecindado en la parroquia de Santiago, fue hijo de Urban de Peralta y Catalina de Valera, siendo uno de sus hermanos el contador Luis de Peralta que, como él, también ocupó con anterioridad la depositaría ${ }^{9}$.

De origenes dudosos, la familia hubo de litigar su hidalguia contra los vecinos del madrileño pueblo de Rejas, pleito del que salieron victoriosos, obteniendo el 13 de enero de 1586 una sentencia definitiva de chijosdalgos notorios en posesión y propiedad, con expresas palabras de notoriedad", para lo que habian aludido a su parentesco con los marqueses de Falces, título procedente del reino de Navarra ${ }^{10}$. Sus familiares, los Barrionuevo, vecinos también de Madrid y de los más acaudalados, por cierto, pleitearon asimismo la hidalguía, pero ellos contra el pueblo de Barajas".

\footnotetext{
7 Testamento de Catalina de Vivero, primera esposa de Gabriel de Alarcón, APM, Prot. 2466 , f. 878 , año 1620

${ }^{8}$ Peralta ingresó en el concejo madrileño el 28 de septiembre de 1584, por renuncia del banquero Antonio Vázquez Vuelta; cesó el 14 de junio de 1585, renunciando a favor de su primo, Jerónimo Barrionuevo de Peralta. AVM, Libros de Acuerdos, sesiones de las fechas mencionadas.

9 Ibidem, sesiones del 6 de agosto de 1564 y 22 de abril de 1575; en este caso, ingresó por renuncia del licenciado Garcia Barrionuevo de Peralta y dejó el cargo en manos de Francisco Barrionuevo, hijo del anterior.

${ }^{10}$ Archivo de la Real Chancilleria de Valladolid (ACV), Sala de Hijosdalgo,1367.13.

11 lbidem, 303.1
} 
El licenciado Francisco de Peraita, y quizá no podia ser de otro modo, contrajo matrimonio con María de Sardaneta y Mendoza, hija del contador y regidor madrileño San Juan de Sardaneta y de Juana de Mendoza, familia originaria de las Vascongadas que, como ellos, se habian visto obligados a probar su dudosa hidalguia ante los vecinos de Torrejón de Ardoz, donde habian acumulado una buena fortuna ${ }^{12}$. Un matrimonio, por tanto, de origenes sociales muy parecidos, con diversas y numerosas vinculaciones al gobierno municipal madrileño y con un patrimonio nada despreciable - María, por ejemplo, aportó como dote a la sociedad conyugal algo más de cuatro millones de maravedies ${ }^{13}$ - No obstante su fortuna personal, el matrimonio, como tantos otros de la época, vivió muy por encima de sus posibilidades económicas con tal de ostentar una posición en el escalafón social madrileño. En su vivienda no faltaron los criados y hay incluso un esclavo tasado, por cierto, en 600 reales. Los muebles, sin ser excesivamente lujosos, están labrados en finas maderas procedentes de las Indias. Vistosos tapices abrigan las paredes; cuadros de inspiración religiosa, valorados casi en 15.000 reales, adornan las estancias; objetos de oro, plata y joyas evaluados en algo más de 19.000 reales completan, en fin, el ornato de la vivienda. Este boato, que implica grandes desembolsos, sin contar los ocasionados por el servicio a la Corona, explica que al fallecer en 1618 don Francisco de Peralta estuviera tan endeudado que ni siquiera pudiera hacer frente a las facturas derivadas de su fatal enfermedad, es decir, el pago de los fármacos y los honorarios del médico ${ }^{14}$.

\section{LA BIBLIOTECA DEL LICENCIADO FRANCISCO DE PERALTA: SU COMPOSICIÓN}

El interés que nuestro regidor madrileño manifiesta por la lectura se evidencia en su rica biblioteca a la que destina una parte importante de su patrimonio (20.294 reales). No es sólo la más valiosa de cuantas poseen los capitulares de la Villa y Corte, sino que los 700 títulos y los 1.175 volúmenes que la componen sobrepasan, en unos casos, y se aproximan en otros, al valor de las colecciones de los más altos funcionarios de los Consejos. No cabe duda que el gusto por la lectura y, por tanto, la po-

\footnotetext{
12 Ibidem, 794.16.

${ }^{13}$ APM, Prot. 3300, f. 1398,10 de noviembre de 1611.

14 Ibidem, 3770, f. 867, 25 de enero de 1618
} 
sesión de libros viene condicionada, además de lo antedicho, por las fortunas de sus titulares. Poca información nos han ofrecido los inventarios al respecto. Con todo, nos sirve de indicativo para conocer la tendencia y comprobar cómo está a la altura de algunas de los consejeros de Castilla y cómo es más rica, por citar un ejemplo, que las de los regidores Iorquinos del siglo $\mathrm{XVII}^{15}, \mathrm{y}$, por supuesto, que las de sus colegas madrileños que no suelen superar los 4.000 reales ${ }^{16}$.

Pese a todo, según se muestra en el Cuadro 1, sólo una obra de la biblioteca del licenciado Peralta se tasó por encima de los 1.200 reales (Tratado de los Doctores Nuevos, en veintinueve cuerpos), mientras que la gran mayoria de ellas valen menos de 20. Este predominio de obras de menor precio, que ratifica la ausencia de ediciones raras o preciosas, lo encontramos también en otras bibliotecas de aquellos años, como en la del presidente del Consejo de Indias, Juan Ovando, ya que el título más caro no superó los 90 reales ${ }^{17}$.

CUADRO 1. VALOR DE LAS OBRAS DEL LICENCIADO PERALTA SEGÚN LAS TASACIONES DEL LIBRERO MARTIIN DE CÓRDOBA *

\begin{tabular}{|c|c|c|}
\hline & NÚMERO & PORCENTAJE \\
\hline De 1 real a 20 reales & 400 & 61,5 \\
\hline De 20 a 30 reales ........................... & 97 & 14,9 \\
\hline 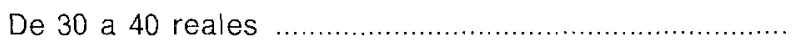 & 42 & 6,5 \\
\hline 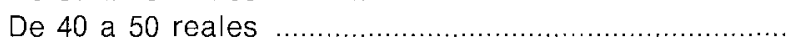 & 35 & 5,4 \\
\hline De 50 a 60 reales & 10 & 1,0 \\
\hline De 60 a 70 reales & 6 & 1,5 \\
\hline De 70 a 80 reales & 7 & 1,1 \\
\hline De 80 a 90 reales & 13 & 2,0 \\
\hline 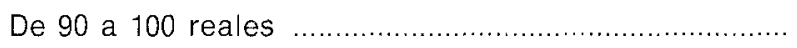 & 17 & 2,6 \\
\hline De 100 a 300 reales & 18 & 2,8 \\
\hline 다 & 4 & 0,6 \\
\hline
\end{tabular}

Fuente: APM, Prot. 3770, f. 867, 25 de enero de 1618.

* Únicamente están tasadas 650 obras del total de la libreria.

${ }^{15}$ Fayard, J., Ob. cit., pág. 463. Cerda Diaz, J., Libros y lecturas en la Lorca del siglo XVII. Murcia 1986, págs. 117 y ss.

${ }^{16}$ Guerrero Mayllo, A., Familia y vida cotidiana de una élite de poder: los regidores madrileños en tiempos de Felipe I/ (en prensa).

${ }_{17}$ Bouza F. J., y Alvar, A., «Apuntes biográficos y análisis de la biblioteca de un gran estadista hispano del siglo XVI: el presidente Juan de Ovando", Revista de Indias, XLIV, 173 (1984) pág. 100. 
Como otras muchas bibliotecas, la de don Francisco de Peralta responde a unas necesidades muy concretas: facilitar a su poseedor en todo momento la información que necesita en el ejercicio de su actividad. Desde luego, sabemos que para el desempeño del cargo municipal no hubo de emplearlos ya que, como el resto de los regidores letrados, sus intervenciones son escasas y, además, para problemas de índole juridica existía en el Ayuntamiento un personal especializado ${ }^{18}$. Sin embargo, al ostentar el puesto de relator del Consejo y Cámara de Su Majestad, sí parece lógico que los utilizara $y$, sospechamos, que profusamente. Semejante fenómeno ha sido señalado por Gelabert en su estudio sobre las librerias de los letrados santiagueses - por cierto, que la media de títulos es algo inferior a la de los regidores madrileños analizados- y por Fayard para los consejeros de Castilla: en el primer caso, las obras dedicadas a materias juridicas oscilan en torno al 73 por 100; en el segundo, se elevan al 85 por $100^{19}$. Evidentemente cuando los propietarios no son licenciados, las librerías presentan más variación y encontramos desde títulos sobre física y caballeria, hasta composiciones musicales, pasando, como no podia ser de otra manera, por los clásicos devocionarios y libros piadosos ${ }^{20}$. Un hecho significativo es que la mayoria de las obras estaban escritas en latín - todavía a mediados del siglo xvı esta lengua era la más utilizada en los estudios científicos-o en castellano, y muy pocos títulos en otros idiomas europeos, con la excepción del italiano.

Volviendo a la biblioteca del regidor madrileño, el 82,9 por 100 de los títulos se ocupaba de materias relacionadas con el Derecho. Asi, hallamos los compendios mejores de la época sobre Derecho Romano, con autores de la talla de Baldo, Bartolo, Socimo, Corneo, Jasón, Imola, Budeo y Decio que vienen a sintetizar todo el saber que desde el Medievo se había ido desarrollando sobre la materia. Los tratados de Derecho Canónico son, asimismo, numerosos. No faltan las obras de Agustín de Barbosa ${ }^{21}$ o Joan Andreas. Aparecen dos importantes y voluminosas colecciones: el Corpus civile (6 cuerpos) y el Corpus Canonicum (13 cuerpos). Junto a ellas, las trecuentes Summas de destacados eruditos (Summa de exemplis, Summa Silvestrina, Summa Tabienis, Summa de Confe-

\footnotetext{
i8 Guerrero Mayllo, A., Los regidores de la Villa y Corte (1560-1606), (en prensa).

10 Gelabert, J. E., "Lectura y escritura en una ciudad del siglo xvl: Santiago de Compostela", La ciudad Hispánica durante los siglos xlli al xvi. Madrid 1985, tomo I, págs. 161-182. FAYARD, J., op. cit., pág. 467.

20 Guerrero Mayllo, A., Familia..., op. cit.

${ }^{21}$ Remisiones Doctorum qui varia logica concili Tridentini incidentes tractarunt. Valladolid 1621.
} 
CUADRO 2. DISTRIBUCIÓN POR MATERIAS DE LOS LIBROS QUE INTEGRABAN LA BIBLIOTECA DE FRANCISCO DE PERALTA

\begin{tabular}{|c|c|c|}
\hline & NÚMERO & PORCENTAJE \\
\hline Lecturas civiles ................ & 50 & 7,1 \\
\hline 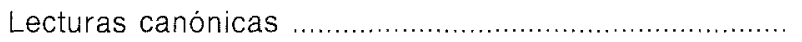 & 29 & 4,1 \\
\hline 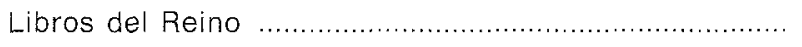 & 140 & 20 \\
\hline 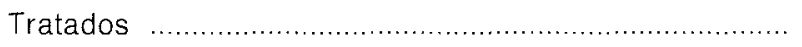 & 103 & 14,7 \\
\hline Decisiones & 44 & 6,3 \\
\hline Consejos & 105 & 15 \\
\hline Prácticas & 20 & 3 \\
\hline 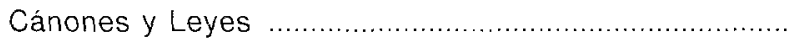 & 133 & 19 \\
\hline 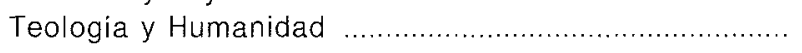 & 76 & 10,8 \\
\hline SUMAS & 700 & 100 \\
\hline
\end{tabular}

sión de Fray Antonio de Florencia, Summa Sacramentorum Ecclesiae de Vitoria, etc.).

Bajo el epígrafe de «Libros del Reino», tal como aparece en el inventario, se agrupan los textos legislativos antiguos y modernos de la Monarquia española, a menudo glosados por los juristas de comienzos del siglo xvı. Así, figuran las Partidas de Alfonso el Sabio, comentadas por Gregorio López ${ }^{22}$, las Leyes de la Mesta, los Fueros de Vizcaya y las Leyes de Toro, con glosas de Tello Fernández de Mesia ${ }^{23}$, Antonio Gómez ${ }^{24}$, Miguel Cifuentes ${ }^{25}$ y Juan Guillén de Cervantes ${ }^{26}$. Cabe destacar los comentarios a diferentes pragmáticas, como la del Pan o la de los Labradores, comentada por Collantes, y sobre todo, la exégesis a la Nueva Recopilación redactada por el licenciado Juan de Matienzo, padre del regidor madrileño y letrado Bernardino de Matienzo. Hemos de mencionar, también, los comentarios de Juan López de Palacios Rubio a las Leyes de Toledo $^{27}$, las glosas de Alfonso Díaz de Montalvo al Fuero Real ${ }^{28}$ o las de Cristóbal de Paz a las Leyes de Estilo ${ }^{29}$. Igualmente apa-

22. Las siete Partidas del sabio Rey Alfonso nuevamente glosadas por el licenciado Gre. gorio López. Salamanca 1555.

${ }^{23}$ Prima pars commentariorum in constitutiones Taurinas. Granada 1566.

${ }^{24}$ In leges Tauri commentarios. Salamanca 1555.

${ }^{25}$ Glosas... sobre las leyes de Toro, quaderno de las leyes. Medina del Campo 1546.

26 Prima pars commentariorum in leges Tauri. Mantuae Carpetanae 1594.

ap Opera Varia, 1616.

28 Ordenanzas Reales, ediciones de 1513, 1518, 1528, 1536.

29 Scholia ad Leges Regias Stili. Madrid 1608. 
recen diversas exégesis de diferentes leyes por Avendaño, Rojas, Pinedo, Villalpando, Rodrigo Suárez, etc.

El máximo representante del regalismo español del siglo xvı, Covarrubias, figura en esta y en la mayor parte de las bibliotecas de nuestros regidores, lo mismo que la obra de Jerónimo Castillo de Bobadilla, Politica para Corregidores y Señores de Vasallos. El interés por cuestiones relacionadas con los origenes y cualidades de la nobleza queda de manifiesto en el tratado de Juan Arce de Otalora, De nobilitatis et inmunitatis Hispaniae Causis, del año 1553. En cuanto al mayorazgo, la obra más utilizada es la de Melchor Peláez de Mieres, Tractatus majoratuum et meliorationum Hispaniae, de 1575. Las cuestiones mercantiles, el problema de la usura y la pobreza, están a su vez representados en dos estudios significativos para su tiempo, en la Suma de Tratos y Contratos de Tomás de Mercado y en Amparo de Pobres, de Pérez de Herrera.

Pese a los títulos mencionados, se observa una cierta especialización en diferentes temas jurídicos, quizá porque en algún momento de su vida pudo dedicarse al despacho de asuntos concretos en materias civiles y mercantiles con obras sobre el mayorazgo, el usufructo, el interés, las alcabalas, juros y censos, lo que en modo alguno quiere decir que queden excluidas otras especialidades de su biblioteca ${ }^{30}$. Entre los manuales prácticos, útiles para el ejercicio de su profesión encontramos el Tractatus de Officio fiscalis de Francisco de Alfaro, impreso en Valladolid en 1606, las Definiciones de Calatrava (sin que tengamos constancia de la pertenencia del regidor a dicha Orden), Modo de examinar procesos, Manuales de los visitadores, las Constituciones del Colegio de Alcalá y la Visita de Cárcel de Cordana.

El escaso porcentaje de libros dedicados a otros asuntos nos permite, no obstante, encontrar un ejemplar de la Biblia Sacra, así como comprobar que el impacto de la Contrarreforma católica y la revisión de los dogmas se pone de manifiesto en distintas obras sobre el Concilio de Trento. Las historias de mártires y de santos se recogen en el Flos Sactorum de Pedro de Ribadeneira y adquieren también su protagonismo las obras de Fray Luis de Granada.

Aunque ignoramos vinculación alguna de Peralta al Santo Oficio, ello no impide que tenga tratados sobre distintas cuestiones relativas a la ortodoxia y a los procedimientos que los pesquisidores deben utilizar para

Asi por ejemplo PIZARro, D., Tratado nuevamente hecho sobre los censos al quitar, a manera de glosa.. Amador Rodriguez, Tractatus de concursu et privilegiis creditorum. Madrid 1616 
averiguar si existen o no desviaciones de la misma. Entre estos tratados, muy frecuentes en las bibliotecas de los regidores letrados, figuran los clásicos directorios, prácticas e índices de inquisidores, junto a otros de autores más modernos como Diego de Simancas, Alfonso de Castro, Arnaldo de Alberti, Gonzalo de Villadiego, Luis de Páramo o Francisco Suárez. Asimismo, y debido al amplio campo de actividad de la Inquisición española, nuestro regidor adquiere una serie de obras relacionadas con la brujería - Malleus Maleficorum-, la hechiceria -Lectura de manos-, o con el luteranismo, sobresaliendo el libro de Johan Von Eck, Enchiridion locorum communium adversus Lutherum et alios hostes Ecclesiae, uno de los más encarnizados enemigos de las doctrinas de Lutero ${ }^{31}$.

Por lo que respecta a los libros históricos, su presencia es tan escasa que más parecen responder a un tipo de lectura para llenar los ratos de ocio que para el adoctrinamiento; así, junto a la obra de Ayala, De jure et officis bellicis et disciplina militari (Amberes 1597), representativa de la historia militar, figuran los Anales de Valencia y Aragón, además de unos volúmenes de la Historia de España del padre Mariana; una Historia Romana y otra Historia Ylustrata.

De otro lado, el impacto del Humanismo y el interés por la literatura grecolatina no están del todo ausentes en las lecturas del licenciado Peralta, ya que cuenta con algunos volúmenes de escritores clásicos y del Renacimiento. En efecto, entre los historiadores encontramos a Plutarco y Cornelio Tácito, muy en boga el último en la España de los siglos XVI y XVII; entre los poetas y dramaturgos a Catulo, Ovidio, Horacio, Terencio y Juvenal. No faltan las obras de Plinio ni las de Cicerón y tampoco las del gran filósofo del pasado Séneca.

Por último, Erasmo queda representado por dos títulos: los Adagios y el Enchiridion. Señalemos, en fin, la ausencia de obras de literatura española, de ciencias o gramática.

\section{INVENTARIO DE LOS LIBROS DEL LICENCIADO FRANCISCO DE PERALTA}

La relación que presentamos seguidamente es una transcripción fiel de los títulos y autores que componen la librería estudiada, según aparecen en el documento manuscrito por el escribano Bernardo de Herbón.

${ }^{31}$ Gil Fernández, L., op. cit., págs. 429-467. 
1. Lecturas civiles

\begin{tabular}{|c|c|c|}
\hline LIBRO O AUTOR & $\begin{array}{l}\text { NUMMERO } \\
\text { CUERPOS }\end{array}$ & $\begin{array}{l}\text { VALOR } \\
\text { (EN RS.) }\end{array}$ \\
\hline Repetitiones Doctorum & 9 & 380 \\
\hline Bartulos ......................... & 10 & 121 \\
\hline Paulus .... & 9 & 88 \\
\hline Jassones ... & 9 & 100 \\
\hline Alexandros ... & 5 & 77 \\
\hline Salicetos ........ & 5 & 66 \\
\hline 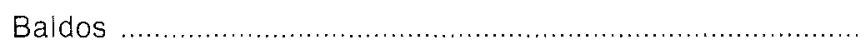 & 8 & 121 \\
\hline Ludovicos Romanos ... & 4 & 50 \\
\hline Angelos & 4 & 60 \\
\hline 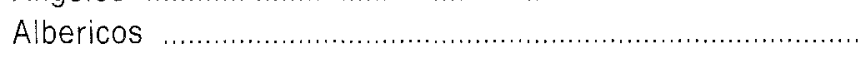 & 9 & 150 \\
\hline Dictionario de Alberico ................ & 1 & 30 \\
\hline Odofredos & 7 & 80 \\
\hline Ripas, Lectura .................. & 2 & 36 \\
\hline Cino, Super Codici ............... & 2 & 40 \\
\hline 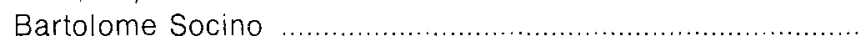 & 2 & 30 \\
\hline 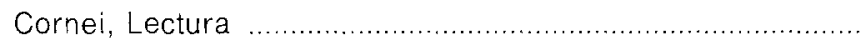 & 3 & 36 \\
\hline Mariano, Socino, super ff. .................. & 1 & 25 \\
\hline 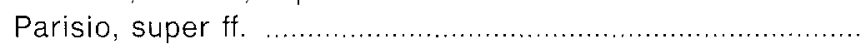 & 1 & 22 \\
\hline 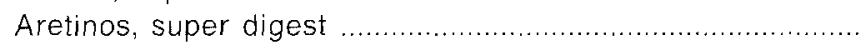 & 2 & 50 \\
\hline 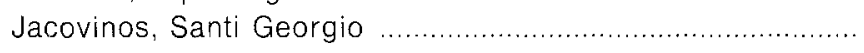 & 2 & 44 \\
\hline Cumanio y Fulgo, con el Código & 6 & 100 \\
\hline Marco Aquilino .............................. & 1 & 26 \\
\hline Hipólito de Marsil .......................... & 1 & 22 \\
\hline 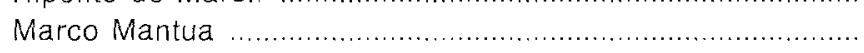 & 2 & 44 \\
\hline 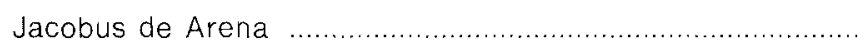 & 1 & 22 \\
\hline 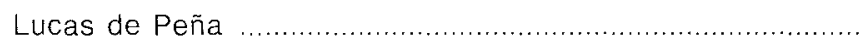 & 1 & 26 \\
\hline 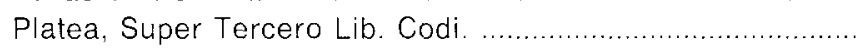 & 1 & 26 \\
\hline 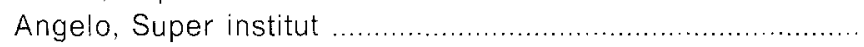 & 1 & 20 \\
\hline Butricano, Supercodi & 1 & 20 \\
\hline 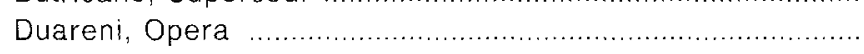 & 2 & 36 \\
\hline 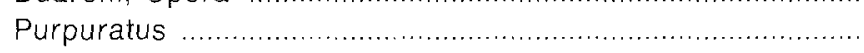 & 2 & 30 \\
\hline Philippus, super digest et codi. ........... & 1 & 20 \\
\hline Summa aconis cumbrocard. ............................ & 1 & 22 \\
\hline Igneos, Lectura & 3 & 40 \\
\hline 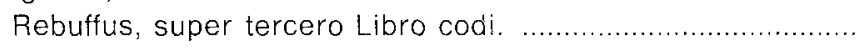 & 1 & 14 \\
\hline 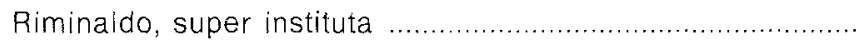 & 1 & 15 \\
\hline 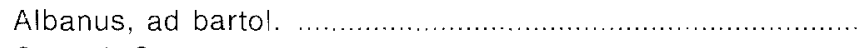 & 3 & 50 \\
\hline 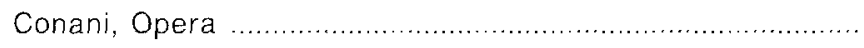 & 1 & 22 \\
\hline 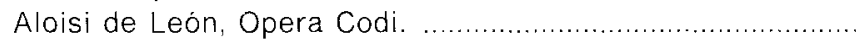 & 1 & 32 \\
\hline Riminaldo, super ff. & 1 & 10 \\
\hline Bologneti, repet. & 6 & 132 \\
\hline
\end{tabular}


Un regidor madrileño instruido en leyes ...

\begin{tabular}{|c|c|c|}
\hline LIBRO O AUTOR & $\begin{array}{l}\text { NUMMERO } \\
\text { CUERPOS }\end{array}$ & $\begin{array}{l}\text { VALOR } \\
\text { (EN RS.) }\end{array}$ \\
\hline Goffredo, Lectura ..................... & 6 & 100 \\
\hline Francisco, Curt Junio & 2 & 36 \\
\hline Caroli Ruin, Lectura ......................... & 3 & 46 \\
\hline 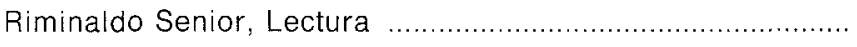 & 1 & 22 \\
\hline Equinauro Varro & 3 & 40 \\
\hline 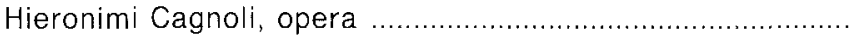 & 2 & 30 \\
\hline 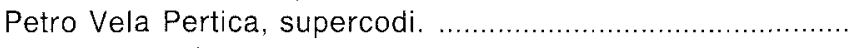 & 1 & 20 \\
\hline Vicencio erculano & 2 & 20 \\
\hline Sicardo, Opera & 2 & 30 \\
\hline
\end{tabular}

\section{LECTURAS CANÓNICAS}

Abbades de los reales .................................................... 9

Felinos ..................................................................... 4

Baldo, superdecreta

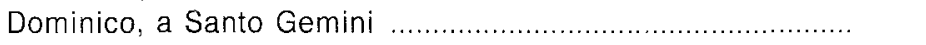

Hostienses .................................................................

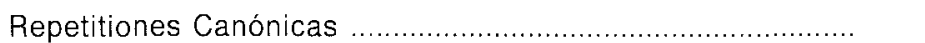

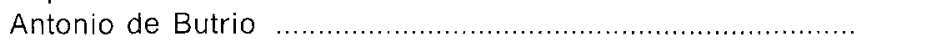

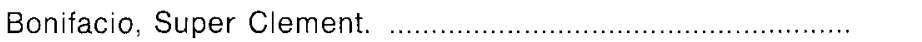

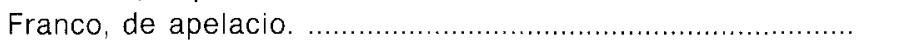

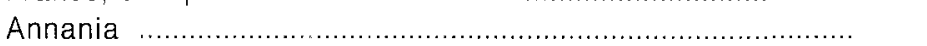

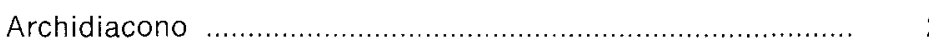

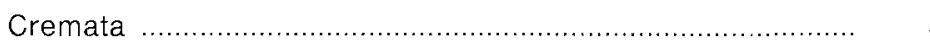

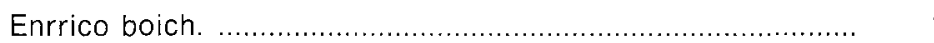

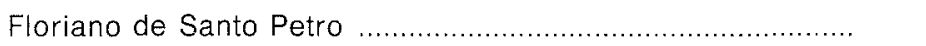

Decio, Super decretalis ....................................................

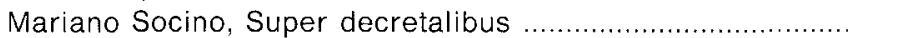

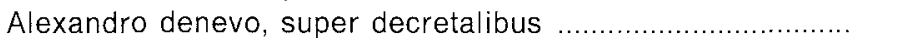

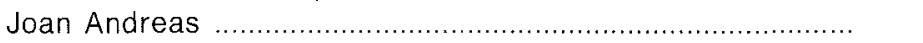

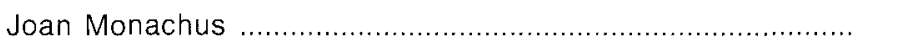

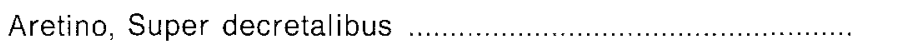

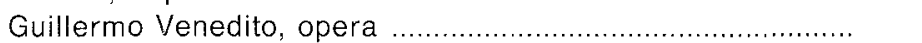

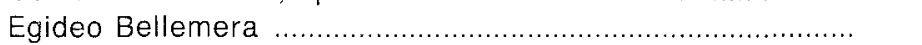

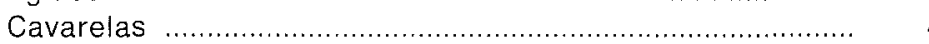

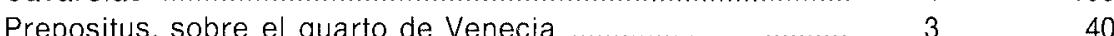

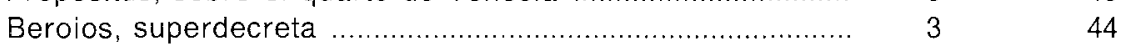

Inocencio, superdecreta ................................................. 118

Ancharrani, lectura ................................................ $\quad 7 \quad 100$

Imola, Superdecreta ................................................ 35 


\begin{tabular}{lrr}
\hline LIBRO O AUTOR & NUMERO & VALOR \\
CUERPOS & (EN RS.) \\
\hline
\end{tabular}

3. LIBROS DEL REYNO

Gregorio López, Superpartit ..................................... 4

Montalvo, Superpartit .............................................. 2

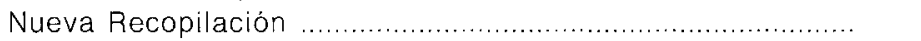

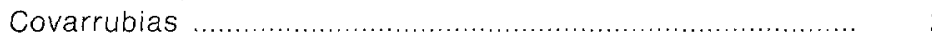

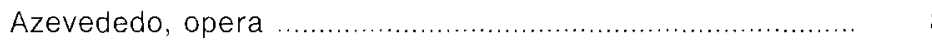

Joan Gutiérrez, opera .............................................. $\quad 10$

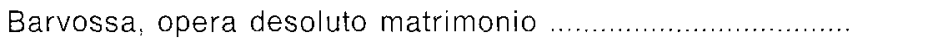

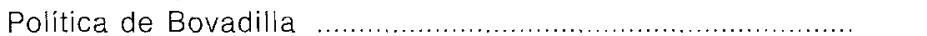

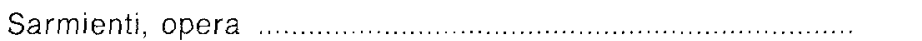

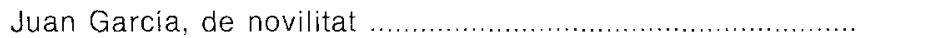

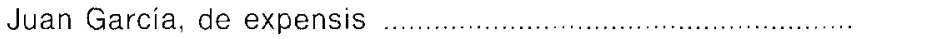

Rodrigo Suárez, opera ..............................................

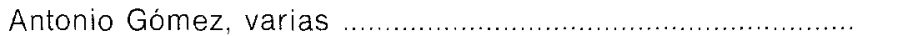

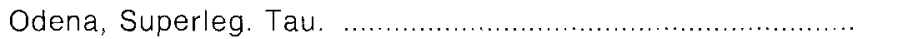

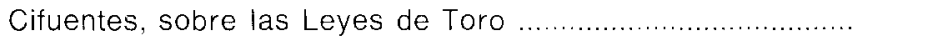

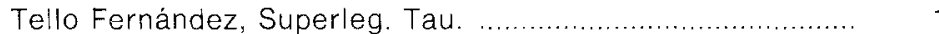

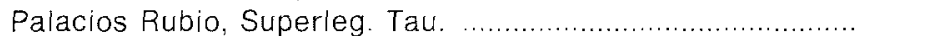

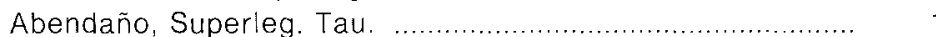

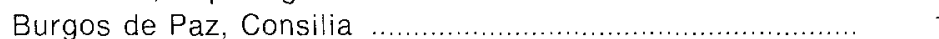

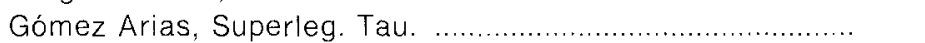

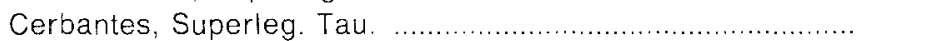

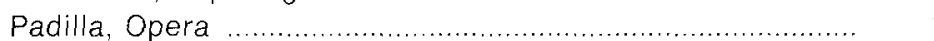

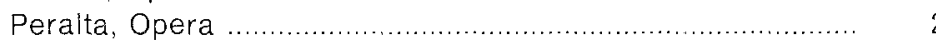

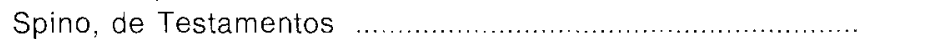

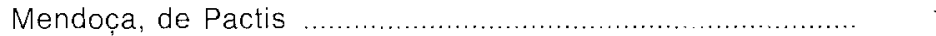

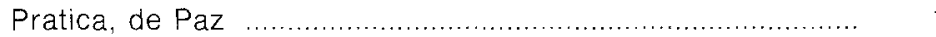

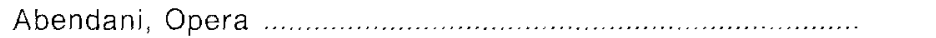

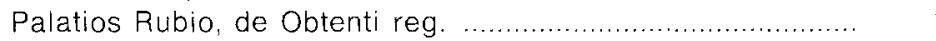

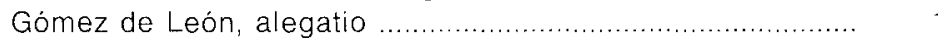

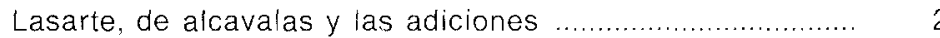

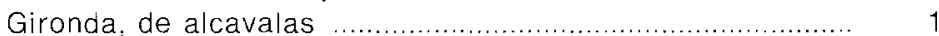

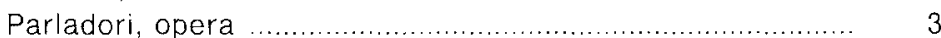

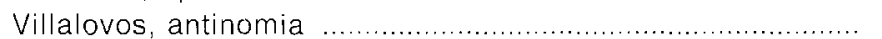

Otalora, de novilitate ................................................ 19

Acosta, Opera ....................................................... 1

Molina de Hispan, Prim. gen. ......................................... 1

Matienço, Super Quinta Recopilación ............................ 1

Matienço, dialogo rela. ........................................ 1

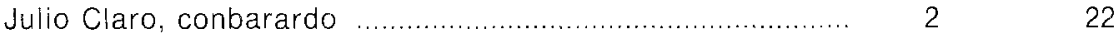

Pineli, opera .......................................................... 12

Repertorio foro Aragón ............................................. 1 
Un regidor madrileño instruido en leyes ...

\begin{tabular}{|c|c|c|}
\hline LIBRO O AUTOR & $\begin{array}{l}\text { NÚMERO } \\
\text { CUERPOS }\end{array}$ & $\begin{array}{l}\text { VALOR } \\
\text { (EN RS.) }\end{array}$ \\
\hline Colectanae, de Çenedo & 1 & 12 \\
\hline Lara, de alimentis ....... & 1 & 12 \\
\hline Cevallos, comunes ...... & 2 & 26 \\
\hline Fuero Juzgo & 1 & 22 \\
\hline 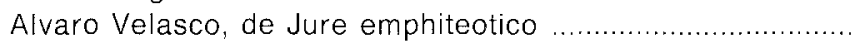 & 1 & 10 \\
\hline Alvaro Velasco, consultaciones et de partitiones ................... & 1 & 20 \\
\hline 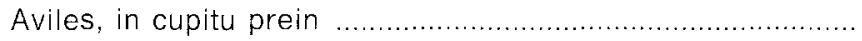 & 1 & 14 \\
\hline Alvarado, de Comet men ....................... & 1 & 9 \\
\hline Salazar, de usu et consuet. ............................... & 1 & 8 \\
\hline Pequera, opera & 3 & 22 \\
\hline 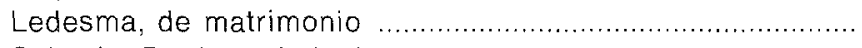 & 1 & 20 \\
\hline Salcedo, Pratica criminal ......................... & 1 & 14 \\
\hline 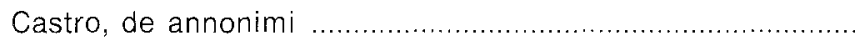 & 1 & 5 \\
\hline 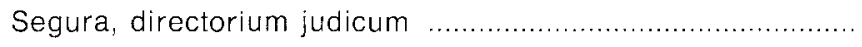 & 1 & 5 \\
\hline 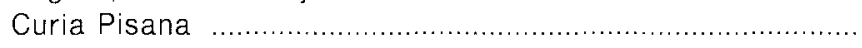 & 1 & 4 \\
\hline 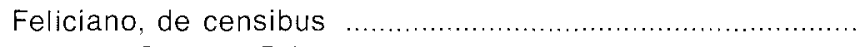 & 2 & 16 \\
\hline Belluga, Speculo Princip. ................ & 1 & 14 \\
\hline Repertorio, Hugo de Celso ................. & 1 & 11 \\
\hline 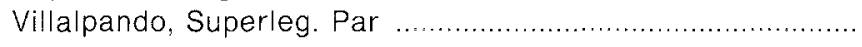 & 1 & 10 \\
\hline 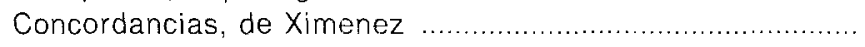 & 1 & 18 \\
\hline 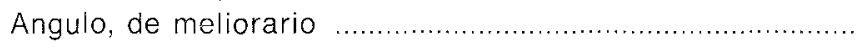 & 1 & 7 \\
\hline 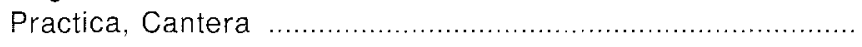 & 1 & 12 \\
\hline Baldes, de dignit. reg. ............................. & 1 & 8 \\
\hline Quintana Duena, opera .......................... & 2 & 14 \\
\hline 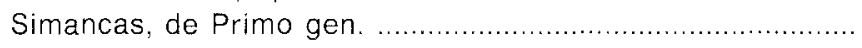 & 1 & 3 \\
\hline Simancas, de Catholic institut. ................. & 1 & 16 \\
\hline Hortigas, patrocinum ................ & 1 & 4 \\
\hline Leon, de servitutibus ................ & 1 & 3 \\
\hline Satiagun, de Judiciis .......................... & 1 & 3 \\
\hline 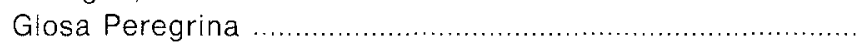 & 2 & 22 \\
\hline Fray Manuel Rodriguez, Questiones .. & 3 & 44 \\
\hline 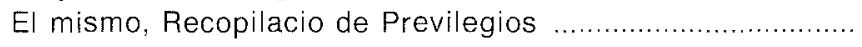 & 1 & 28 \\
\hline 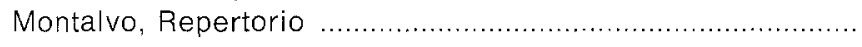 & 1 & 7 \\
\hline 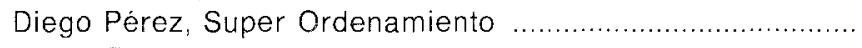 & 2 & 40 \\
\hline 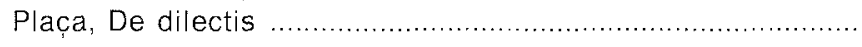 & 1 & 10 \\
\hline 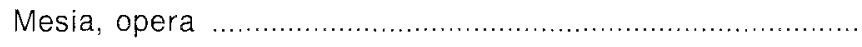 & 2 & 24 \\
\hline 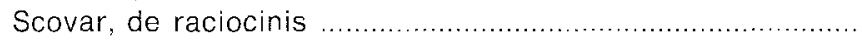 & 1 & 14 \\
\hline 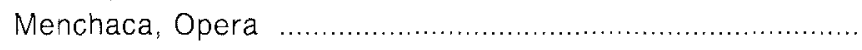 & 5 & 55 \\
\hline 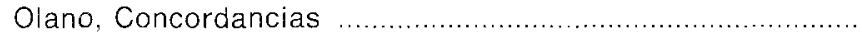 & 1 & 8 \\
\hline Ahumada, super segunda part. .... & 1 & 10 \\
\hline 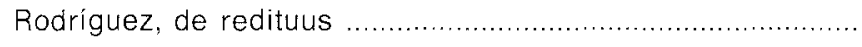 & 1 & 14 \\
\hline 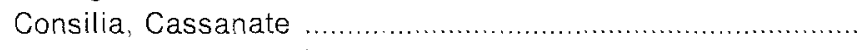 & 1 & 16 \\
\hline Flores, pratica questiones. & 1 & 8 \\
\hline
\end{tabular}




$\begin{array}{lll} & & \\ \text { LIBRO O AUTOR } & \text { NUMERO } & \text { VALOR } \\ & \text { CUERPOS } & \text { (EN RS.) }\end{array}$

Segura, repetitiones 10

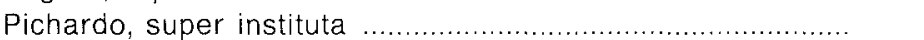

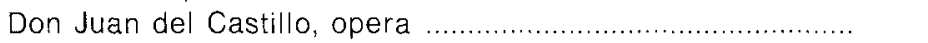

Navarro, opera omnia ..................................................

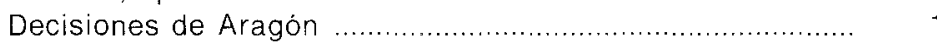

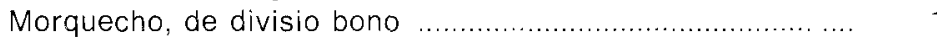

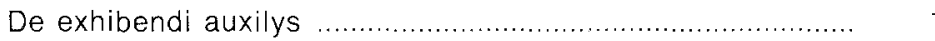

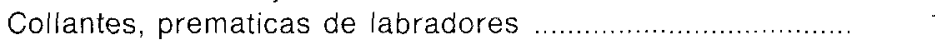

Tapia, opera de constitu. principis et climent. ingresu ........

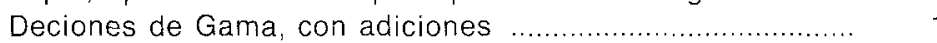

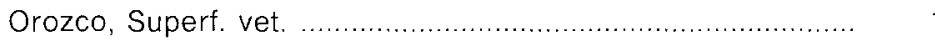

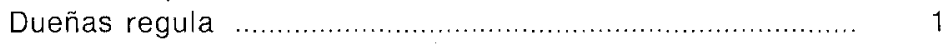

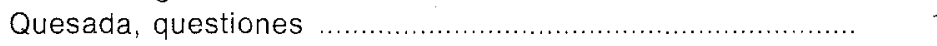

Sánchez, de matrimonio .................................................

González, sobre el alternativa et super ocho leg. cancel. ...

Molina, de Justicia et Judice .............................................

Olivano, de Jure fili ...................................................... 1

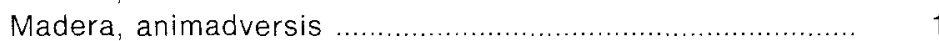

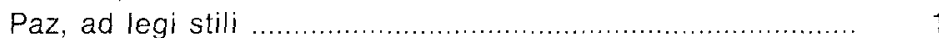

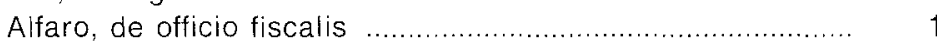

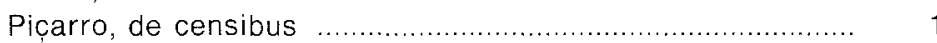

Caldas Pereira, de jure emphiotetico et restitutione ............

Emporium juris ......................................................... 1

Caldera, animadversio ............................................... 1

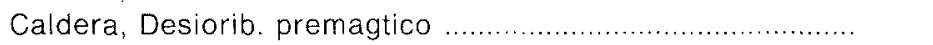

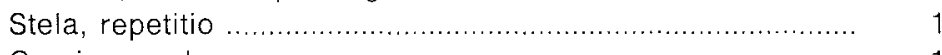

Gracian, reglas ........................................................... 1

Gallego, de parrochori obligat. ......................................

Don Juan Vela, de dilect ....................................................

Monter, de pactis ...........................................................

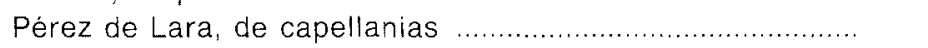

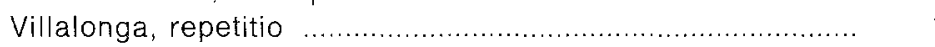

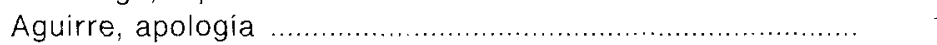

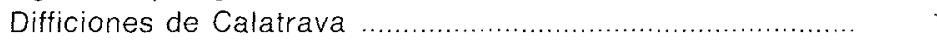

Nicolás Garcia, de Beneficiis ............................................

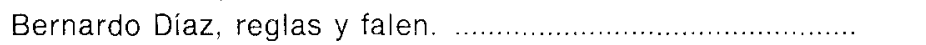

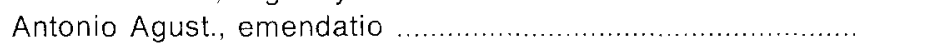

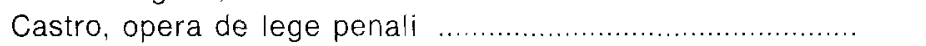

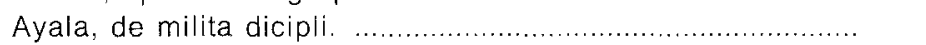

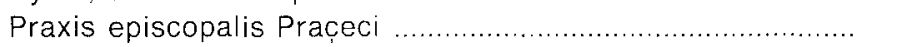

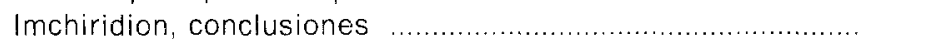

Camilo Berelo, de presta. reg. et regia Aragón ...................

Gómez de Potet, inse ipsum ......................................... 1 
Un regidor madrileño instruido en leyes ...

\begin{tabular}{|c|c|c|}
\hline LIBRO O AUTOR & $\begin{array}{l}\text { NÚMERO } \\
\text { CUERPOS }\end{array}$ & $\begin{array}{l}\text { VALOR } \\
\text { (EN RS.) }\end{array}$ \\
\hline Antonio Roscio, memorialibus. & 1 & 4 \\
\hline Modo de examinar proçessos & 1 & 6 \\
\hline Armonia, Juris cano ................ & 1 & 3 \\
\hline Valençuela, invenctos .................. & 1 & 7 \\
\hline Tratatus de boto & 1 & 4 \\
\hline 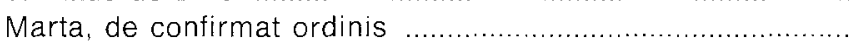 & 1 & 5 \\
\hline Alonso Guerrero, Tesauro xpiane religio. & 1 & 12 \\
\hline 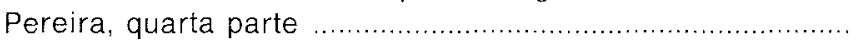 & 1 & 20 \\
\hline 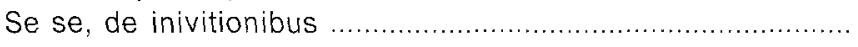 & 1 & - \\
\hline 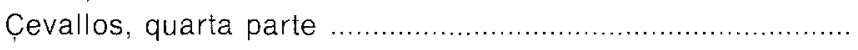 & 1 & 9 \\
\hline Medrano, de consen. & 1 & 4 \\
\hline 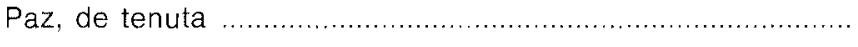 & 1 & 11 \\
\hline \multicolumn{3}{|l|}{ 4. TRATADOS } \\
\hline 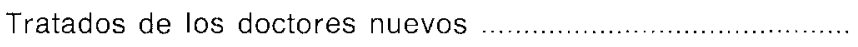 & 29 & 1.200 \\
\hline 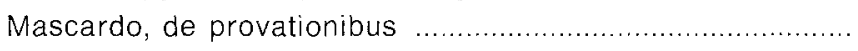 & 3 & 60 \\
\hline $\begin{array}{l}\text { Menochio, de presuncionibus de arvitraris et remedia co- } \\
\text { loma }\end{array}$ & 3 & 77 \\
\hline Surdo, de alimentis & 1 & 26 \\
\hline 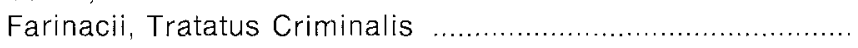 & 7 & 150 \\
\hline 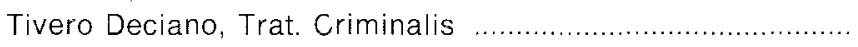 & 2 & 34 \\
\hline 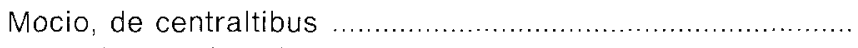 & 1 & 10 \\
\hline 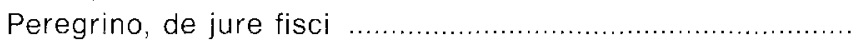 & 1 & 10 \\
\hline 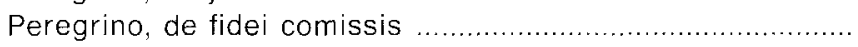 & 1 & 22 \\
\hline Flaminio Parisio, de resignatione et confidentia ................... & 3 & 28 \\
\hline 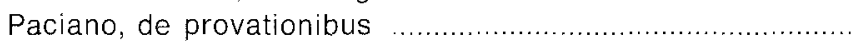 & 2 & 30 \\
\hline 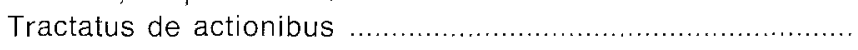 & 1 & 18 \\
\hline 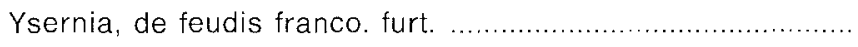 & 1 & 22 \\
\hline 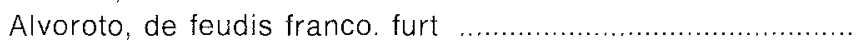 & 1 & 22 \\
\hline 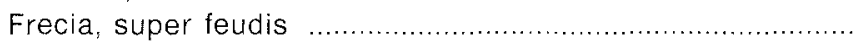 & 1 & 18 \\
\hline 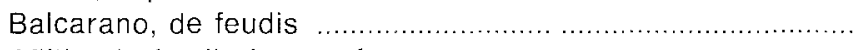 & 1 & 24 \\
\hline 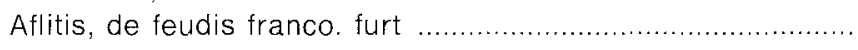 & 1 & 24 \\
\hline 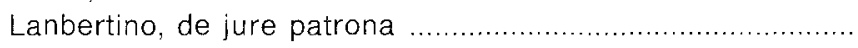 & 1 & 36 \\
\hline 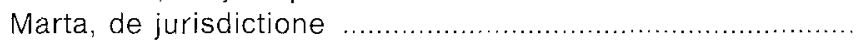 & 1 & 20 \\
\hline Tractatus de integrum restitutionibus franco. furt ................... & 2 & 8 \\
\hline Villaguta, de extensione legum & 1 & 22 \\
\hline 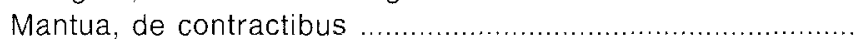 & 2 & 50 \\
\hline Mantua, de conrect, último volumen ..................................... & 1 & 16 \\
\hline 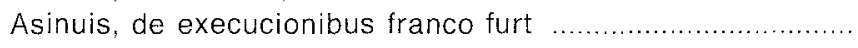 & 1 & 30 \\
\hline 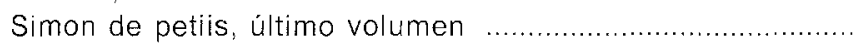 & 1 & 28 \\
\hline 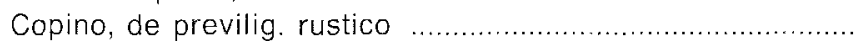 & 1 & 7 \\
\hline Costa de jure et fabigno, franco furt. & 1 & 10 \\
\hline
\end{tabular}




\begin{tabular}{|c|c|c|}
\hline LIBRO O AUTOR & $\begin{array}{l}\text { NÚMERO } \\
\text { CUERPOS }\end{array}$ & $\begin{array}{c}\text { VALOR } \\
\text { (EN RS.) }\end{array}$ \\
\hline Costa, de porcione rata ........... & 1 & 10 \\
\hline Costa, de remedio subsidiario ......... & 1 & 16 \\
\hline Marco Antonio, peregrino variarum ................... & 1 & 10 \\
\hline 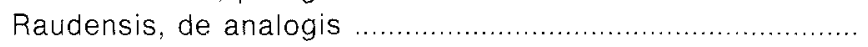 & 1 & 16 \\
\hline 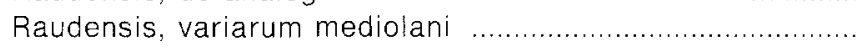 & 1 & 14 \\
\hline Alexandre, trentacin franco fur & 2 & 30 \\
\hline Valganeto, de condicionibus .... & 1 & 12 \\
\hline Ricardi, opera .................................... & 3 & 30 \\
\hline Grasis, recepta sententia, franco fur .......... & 1 & 15 \\
\hline Scapa, de jure no scripto .................... & 1 & 12 \\
\hline 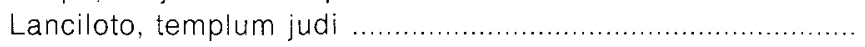 & 1 & 11 \\
\hline 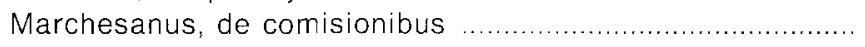 & 1 & 12 \\
\hline 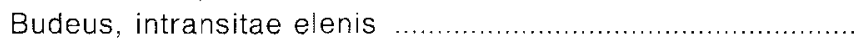 & 1 & 4 \\
\hline Constancio, rogerio opera & 1 & 18 \\
\hline 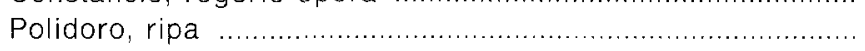 & 3 & 27 \\
\hline Lambertengo, de contractibus .......... & 1 & 14 \\
\hline Marcos Burjen, de aprrupto. ........ & 1 & 8 \\
\hline Antonii Cornei, tractat. ...................... & 1 & 11 \\
\hline Ugo Linus, de usuris ........................ & 1 & 6 \\
\hline 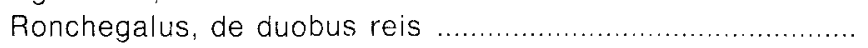 & 1 & 6 \\
\hline Magonio, de recta patrocinum racione, franco furt & 1 & 7 \\
\hline 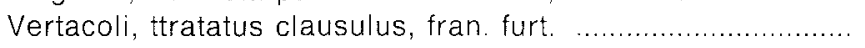 & 8 & 8 \\
\hline 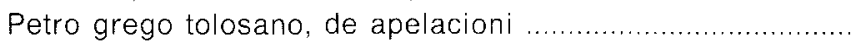 & 4 & 4 \\
\hline 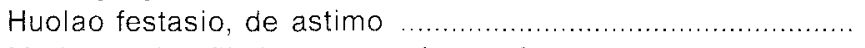 & 1 & 2 \\
\hline 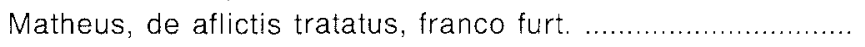 & 1 & 3 \\
\hline Dino y Decio de reg. jure ............................. & 1 & 5 \\
\hline Turelo, de cláusula codicila .................... & 1 & 6 \\
\hline Petus pechius, de reg. jure ............ & 1 & 10 \\
\hline Budeus, de contemptu rer. fortuita ............. & 1 & 4 \\
\hline Nicolao, de posesibus de scriptura privata & 1 & 5 \\
\hline Ortiz, de inmunitate eclesiarum ...................... & 1 & 10 \\
\hline Corbulus, de jure enphiteutico ........................ & 1 & 8 \\
\hline Jacobo Serocio, de vica episcopi ..... & 1 & 7 \\
\hline Paleoto, desairo consilio .............. & 1 & 6 \\
\hline 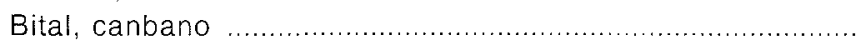 & 1 & 6 \\
\hline Cala, de modo articulandi ... & 1 & 6 \\
\hline Vala, de reuu dubiis .................. & 1 & 5 \\
\hline Virginio, vocatio ttratatus ..................... & 1 & 6 \\
\hline Jacovi beni, de privilegiis ...................... & 1 & 5 \\
\hline Petro, de potestate princip. franco furt. .. & 1 & 14 \\
\hline 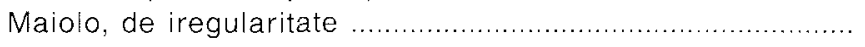 & 1 & 11 \\
\hline 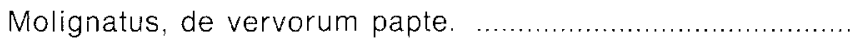 & 1 & 5 \\
\hline 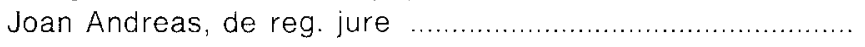 & 1 & 3 \\
\hline
\end{tabular}


Un regidor madrileño instruido en leyes ...

\begin{tabular}{|c|c|c|}
\hline LIBRO O AUTOR & $\begin{array}{l}\text { NÜMERO } \\
\text { CUERPOS }\end{array}$ & $\begin{array}{c}\text { VALOR } \\
\text { (EN RS.) }\end{array}$ \\
\hline 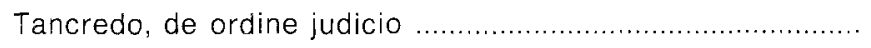 & 1 & 2 \\
\hline Joan de Blabascio, de ordine judicia ................... & 1 & 3 \\
\hline Jilchenio, de usura prohib. franco furt. & 1 & 14 \\
\hline Lacario, de monitoriis ........................... & 1 & 6 \\
\hline Galino, de vervo significa. ...................... & 1 & 16 \\
\hline 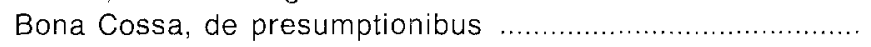 & 1 & 8 \\
\hline 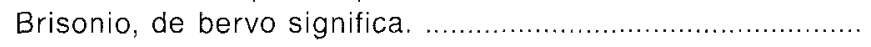 & 1 & 26 \\
\hline Revelo, de berborum obligatio, ....................... & 1 & 32 \\
\hline Pancirolo de utraque noticia ................ & 1 & 16 \\
\hline Petro gregorio, de particionibus ........ & 1 & 18 \\
\hline 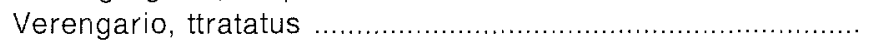 & 1 & 20 \\
\hline 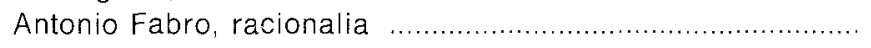 & 1 & 24 \\
\hline Pancirolo, ttratatus varii .................... & 1 & 14 \\
\hline Cepola, ttratatus varii .... & 1 & 20 \\
\hline Jacobo, de feudis ....................... & 1 & 4 \\
\hline 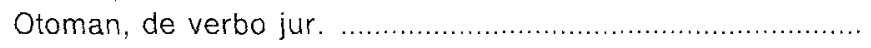 & 1 & 8 \\
\hline 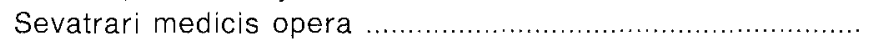 & 2 & 34 \\
\hline 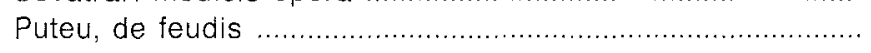 & 1 & 8 \\
\hline Michael de Avinon, de unitate ombris, cesar auguste ......... & 1 & 5 \\
\hline 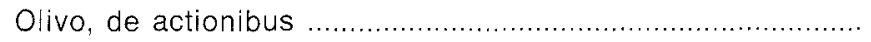 & 2 & 28 \\
\hline 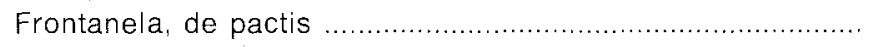 & 1 & 16 \\
\hline 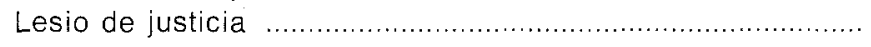 & 1 & 28 \\
\hline 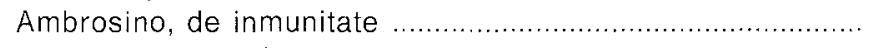 & 1 & 6 \\
\hline 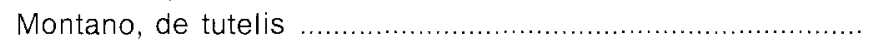 & 1 & 8 \\
\hline 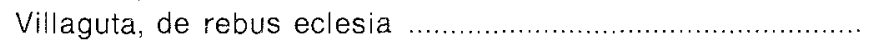 & 1 & 10 \\
\hline 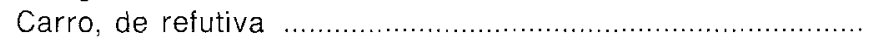 & 1 & 5 \\
\hline Gratinus, de confiscacione venurum ........... & 1 & 10 \\
\hline 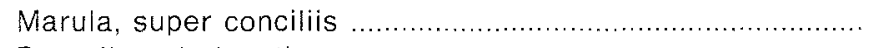 & 1 & 9 \\
\hline 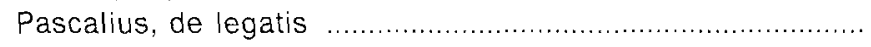 & 1 & 9 \\
\hline Tractatus, de venatie ...................... & 1 & 7 \\
\hline Antonio Fabio, de erroribus ..... & 3 & 33 \\
\hline Escarza, de apelatio & 1 & 30 \\
\hline 5. DECISIONES & & \\
\hline Boerii, decisio ...................... & 1 & 22 \\
\hline Francisci marci, decisio ....... & 2 & 36 \\
\hline Aflictis conusilo ................... & 1 & 26 \\
\hline 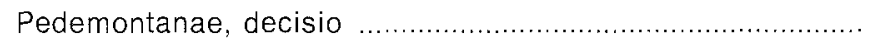 & 2 & 16 \\
\hline 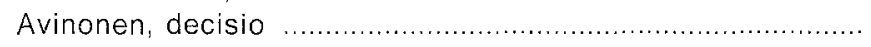 & 1 & 6 \\
\hline 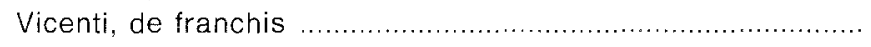 & 1 & 24 \\
\hline 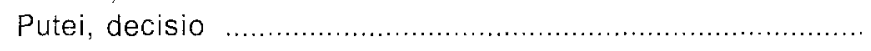 & 1 & 15 \\
\hline 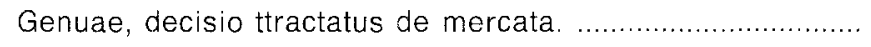 & 1 & 32 \\
\hline
\end{tabular}




\begin{tabular}{|c|c|c|}
\hline LIBRO O AUTOR & $\begin{array}{l}\text { NÚMERO } \\
\text { CUERPOS }\end{array}$ & $\begin{array}{l}\text { VALOR } \\
\text { (EN RS.) }\end{array}$ \\
\hline Decisio canonice diverso .... & 1 & 18 \\
\hline 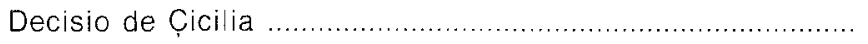 & 1 & 11 \\
\hline Decisio rote & 1 & 18 \\
\hline Surdi decisio ................. & 2 & 22 \\
\hline Rota decissio novisime & 2 & 48 \\
\hline Josephe ludovi ............... & 2 & 12 \\
\hline Guido pape .............................. & 1 & 18 \\
\hline Cavalcani, decisio franco furt .... & 2 & 50 \\
\hline 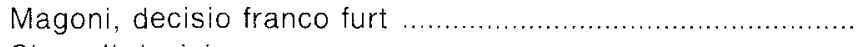 & 1 & 18 \\
\hline Claperii decisio & 1 & 6 \\
\hline 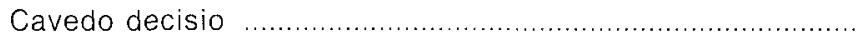 & 1 & 20 \\
\hline 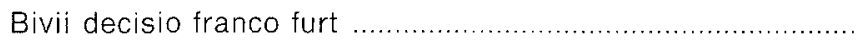 & 2 & 26 \\
\hline Mainardi decisio franco furt ....... & 1 & 20 \\
\hline Cornacani decisio franco furt ............................ & 1 & 18 \\
\hline 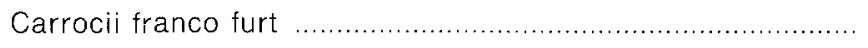 & 1 & 18 \\
\hline 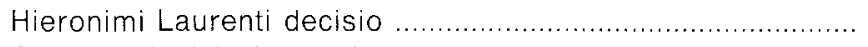 & 1 & 12 \\
\hline 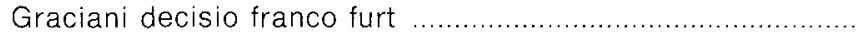 & 1 & 12 \\
\hline Codex fabrianus decisio sabaud franco furt .... & 1 & 33 \\
\hline Estephano Gracian, de sceptaciones forenses ..................... & 2 & 50 \\
\hline 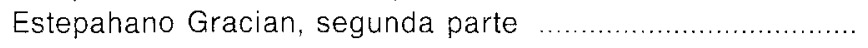 & 1 & 20 \\
\hline 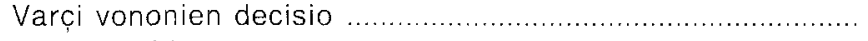 & 1 & 20 \\
\hline 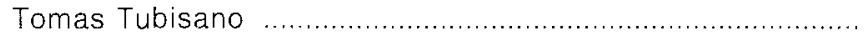 & 1 & 10 \\
\hline Intriglioli decisio $\ldots \ldots \ldots \ldots \ldots \ldots \ldots \ldots \ldots . . . \ldots \ldots$ & 1 & 8 \\
\hline Gramatici decisio ...................... & 1 & 8 \\
\hline Reudensis decisio ...................... & 1 & 16 \\
\hline Sese decisio cesar auguste ....... & 1 & 20 \\
\hline 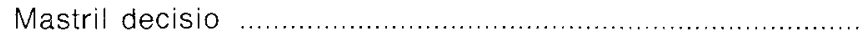 & 2 & 18 \\
\hline 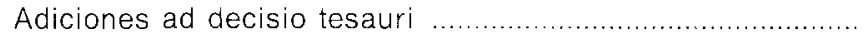 & 1 & 4 \\
\hline 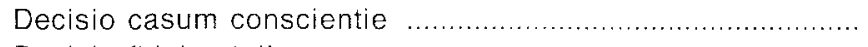 & 2 & 18 \\
\hline 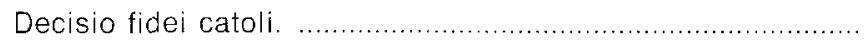 & 1 & 12 \\
\hline 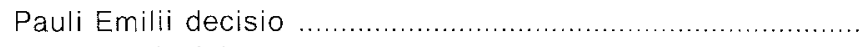 & 1 & 12 \\
\hline Moedani decisio $\ldots \ldots \ldots \ldots \ldots \ldots \ldots \ldots \ldots . . . . . . . . . .$. & 1 & 10 \\
\hline 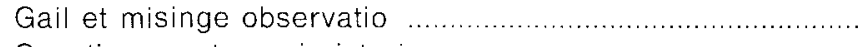 & 1 & 22 \\
\hline 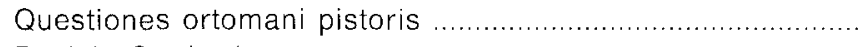 & 6 & 60 \\
\hline Decisio Carthari ..................... & 1 & 8 \\
\hline Deciones seraphini $\ldots \ldots \ldots \ldots \ldots$ & 2 & 36 \\
\hline
\end{tabular}

\section{CONSEJOS}

Baldi consilio …............................................................. 5

Pauli consil. .......................................................

Decii consil. .........................................................

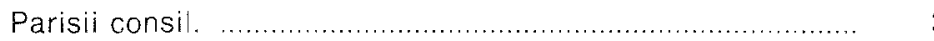


Un regidor madrileño instruido en leyes ...

\begin{tabular}{|c|c|c|}
\hline LIBRO O AUTOR & $\begin{array}{l}\text { NÜMERO } \\
\text { CUERPOS }\end{array}$ & $\begin{array}{l}\text { VALOR } \\
\text { (EN RS.) }\end{array}$ \\
\hline Alexandri consil. ............. & 3 & 88 \\
\hline Jasones consilia & 2 & 33 \\
\hline 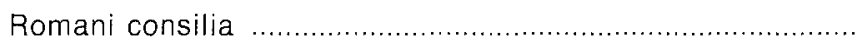 & 2 & 18 \\
\hline Barbatia consilia .......................... & 4 & 44 \\
\hline Cephali consilia & 5 & 100 \\
\hline 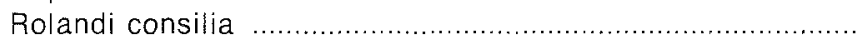 & 4 & 40 \\
\hline Oldraldi consilia ................... & 1 & 14 \\
\hline 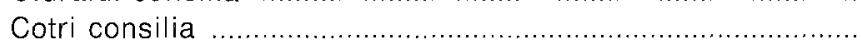 & 3 & 40 \\
\hline 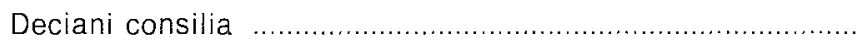 & 5 & 100 \\
\hline Bertandi consilia & 8 & 143 \\
\hline Petrisurdi & 4 & 100 \\
\hline Menochii consilia & 9 & 180 \\
\hline Ruini consilia .............................. & 4 & 80 \\
\hline Riminaldo senior consilia ................. & 3 & 44 \\
\hline Fulvii Pacia consilia .......................... & 1 & 32 \\
\hline 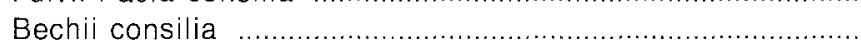 & 2 & 44 \\
\hline Mandeli albens consilia ................. & 2 & 66 \\
\hline 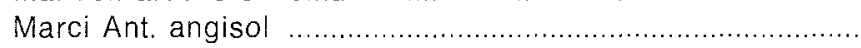 & 1 & 15 \\
\hline 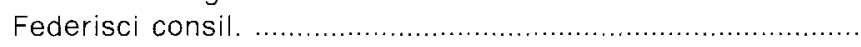 & 1 & 32 \\
\hline Paulo de Montepico consil. ............. & 1 & 22 \\
\hline 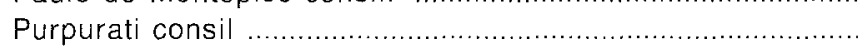 & 2 & 44 \\
\hline Berete consil & 1 & 20 \\
\hline Petri ancharra consil ............ & 1 & 14 \\
\hline 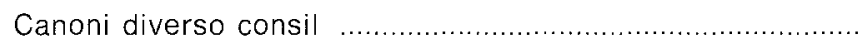 & 1 & 20 \\
\hline 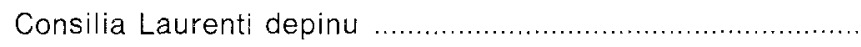 & 1 & 18 \\
\hline Franco de aponte & 1 & 18 \\
\hline 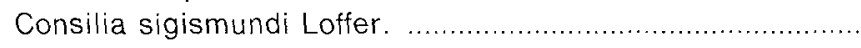 & 1 & 16 \\
\hline Philippi portii consilia ........ & 1 & 20 \\
\hline Nate consilia ....................... & 2 & 36 \\
\hline Thome grammati consil ...... & 1 & 20 \\
\hline Feudalia consil diverso & 1 & 10 \\
\hline 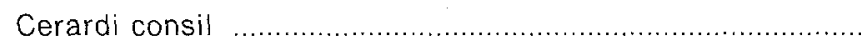 & 1 & 14 \\
\hline Corcherani consilia ................ & 1 & 14 \\
\hline 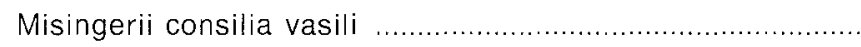 & 1 & 12 \\
\hline 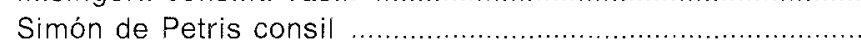 & 2 & 38 \\
\hline 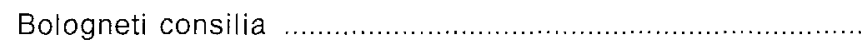 & 1 & 10 \\
\hline 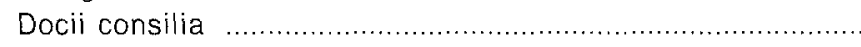 & 1 & 12 \\
\hline Quintiliani mando & 1 & 10 \\
\hline Capre consilia & 1 & 18 \\
\hline 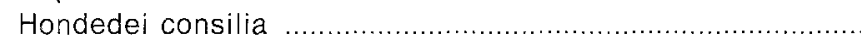 & 1 & 20 \\
\hline 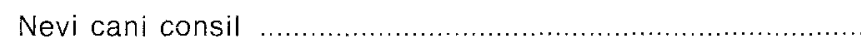 & 1 & 15 \\
\hline 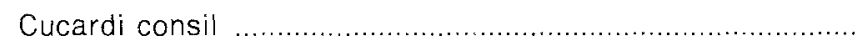 & 1 & 18 \\
\hline 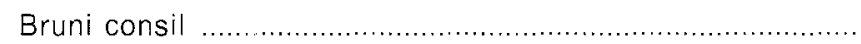 & 1 & 16 \\
\hline
\end{tabular}




\begin{tabular}{|c|c|c|}
\hline LIBRO O AUTOR & $\begin{array}{l}\text { NUMMERO } \\
\text { CUERPOS }\end{array}$ & $\begin{array}{l}\text { VALOR } \\
\text { (EN RS.) }\end{array}$ \\
\hline Celeti consil crimin & 1 & 20 \\
\hline Altrati responsa $\ldots . . \ldots \ldots \ldots \ldots \ldots \ldots . . . \ldots . . .$. & 1 & 26 \\
\hline Alverti Leonini .................. & 1 & 14 \\
\hline Joan Philipi consil ........... & 1 & 10 \\
\hline Bellamera consil ............... & 1 & 12 \\
\hline 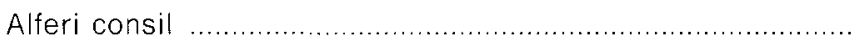 & 1 & 10 \\
\hline 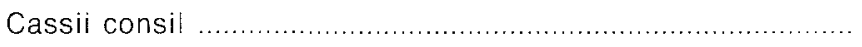 & 1 & 12 \\
\hline 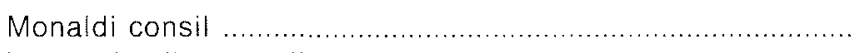 & 1 & 12 \\
\hline 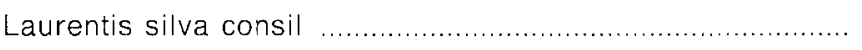 & 1 & 15 \\
\hline Cavarele consil ............ & 1 & 12 \\
\hline Marianensis consil ...... & 1 & 14 \\
\hline Rovert Maran consil. & 1 & 14 \\
\hline Pauli Leonini consil ................ & 1 & 12 \\
\hline Ruvel consil ....................... & 1 & 6 \\
\hline Peregrine consil ................... & 3 & 70 \\
\hline Ipolit demar consil ................ & 1 & 14 \\
\hline J. de Amius consil ................ & 1 & 10 \\
\hline Augustino Veroio consil. & 4 & 100 \\
\hline Curti Junio consil ........... & 2 & 33 \\
\hline Curti senio consil ........ & 1 & 16 \\
\hline 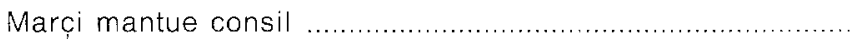 & 2 & 26 \\
\hline 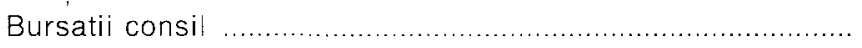 & 4 & 88 \\
\hline 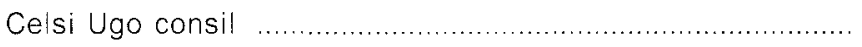 & 1 & 20 \\
\hline 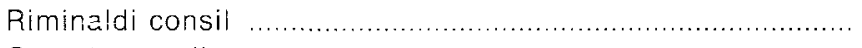 & 7 & 120 \\
\hline 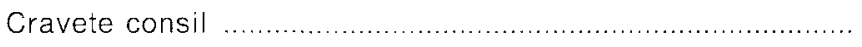 & 5 & 100 \\
\hline Angeli de Ubaldis ............. & 1 & 20 \\
\hline Jerardi Macoli consilia ............ & 1 & 20 \\
\hline Gocadini consil ................................... & 1 & 12 \\
\hline 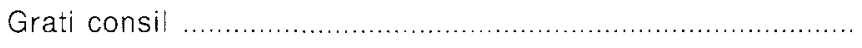 & 1 & 24 \\
\hline 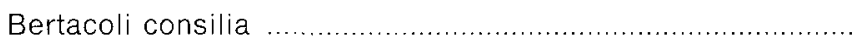 & 3 & 44 \\
\hline 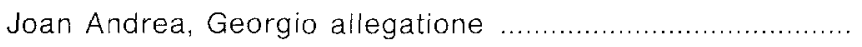 & 1 & 12 \\
\hline 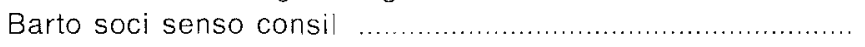 & 4 & 88 \\
\hline 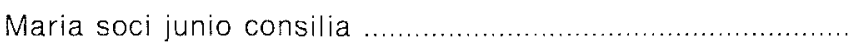 & 4 & 88 \\
\hline Conci consil ......................... & 5 & 100 \\
\hline Prosperi pasethi ,.......... & 1 & 16 \\
\hline 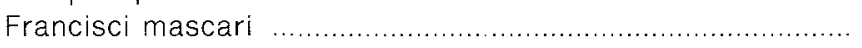 & 1 & 16 \\
\hline 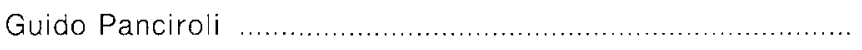 & 1 & 22 \\
\hline 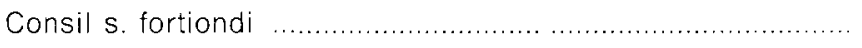 & 1 & 20 \\
\hline 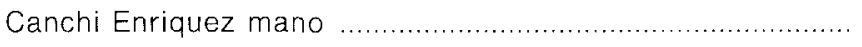 & 3 & 30 \\
\hline 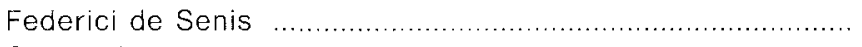 & 1 & 10 \\
\hline Calcanci .................................... & 1 & 12 \\
\hline 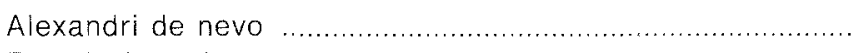 & 1 & 10 \\
\hline 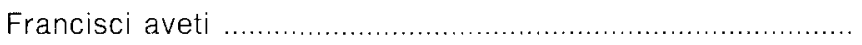 & 1 & 14 \\
\hline
\end{tabular}


Un regidor madrileño instruido en leyes ...

\begin{tabular}{|c|c|c|}
\hline LIBRO O AUTOR & $\begin{array}{l}\text { NÚMERO } \\
\text { CUERPOS }\end{array}$ & $\begin{array}{l}\text { VAL_OR } \\
\text { (EN RS.) }\end{array}$ \\
\hline Bernardo Bonilani & 1 & 12 \\
\hline Guden Pape ......... & 1 & 4 \\
\hline Bardeloni ................... & 1 & 22 \\
\hline 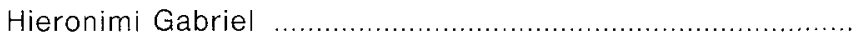 & 2 & 44 \\
\hline Ubamesi & 1 & 18 \\
\hline Coste & 1 & 16 \\
\hline Aldo Ruini & 1 & 20 \\
\hline Sichardi & 1 & 16 \\
\hline Sace & 1 & 16 \\
\hline 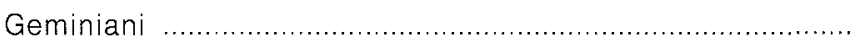 & 1 & 10 \\
\hline Signodolo de omidis compania & 1 & 16 \\
\hline Fulgosi et Cumani & 1 & 12 \\
\hline 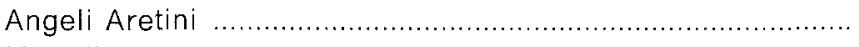 & 1 & 18 \\
\hline 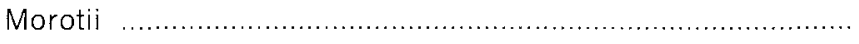 & 1 & 12 \\
\hline
\end{tabular}

\section{PRÁCTICAS}

Patrica morante ........................................................ 1

Egidio Bossio ........................................................... 12

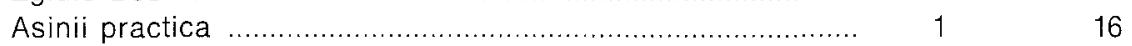

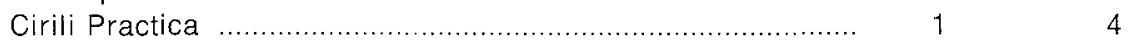

Folerii Practica ......................................................... 1

El dicho, practica cano ............................................... 1 .

Milei practica ................................................................. 1 .

Practica medio lanen .................................................. 113

Fasalane Practica ....................................................... 11

Thomas Cerola Practica episcop. ..................................... 11

Carreri practica .......................................................... 1

Petri Jacovi practica ....................................................... 1

Baltan diez petri ..................................................... 1 (

León Franco Practica ................................................... 1

Ferrari practica ......................................................... 1

Practica Mandossi ..................................................... $1 \quad 30$

Praxis archepiscopalis ............................................... 110

Suma bularum ................................................... 1

Practica rufineli ........................................................... 12

Modicio dubitationes ...................................................... 1

8. DIVERSOS DE CÁNONES Y LEYES

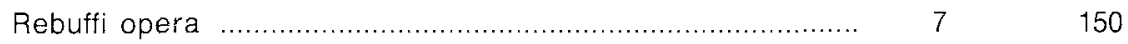

Comunes opiniones ...................................................... $3 \quad 60$

Tiraquelos con alexandro ............................................. 6 


\begin{tabular}{|c|c|c|}
\hline LIBRO O AUTOR & $\begin{array}{l}\text { NÜMERO } \\
\text { CUERPOS }\end{array}$ & $\begin{array}{l}\text { VALOR } \\
\text { (EN RS.) }\end{array}$ \\
\hline Altrati opera vasilei ................................. & 5 & 100 \\
\hline 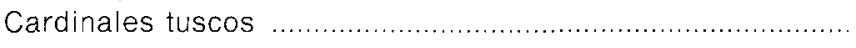 & 8 & 330 \\
\hline 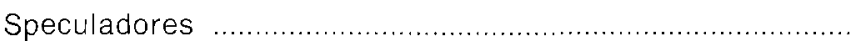 & 2 & 36 \\
\hline 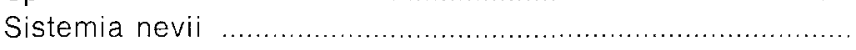 & 4 & 77 \\
\hline 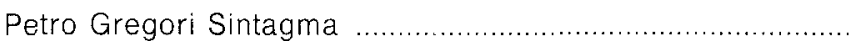 & 3 & 48 \\
\hline Bartachino repert. & 5 & 60 \\
\hline Epistola decretales ................... & 3 & 88 \\
\hline Juris civilis, tomo setimo ......... & 2 & 40 \\
\hline Arismino topato .................. & 2 & 30 \\
\hline 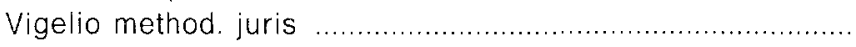 & 1 & 20 \\
\hline Casuneo, opera & 2 & 40 \\
\hline 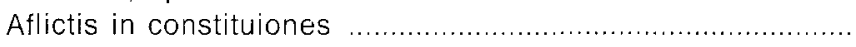 & 1 & 30 \\
\hline 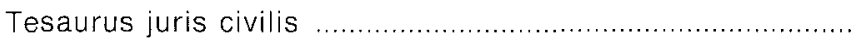 & 1 & 18 \\
\hline Forcatuli, opera ............................... & 1 & 20 \\
\hline Regule venedicti capre .................. & 1 & 15 \\
\hline Brunolie, sole loci comunes ....... & 1 & 16 \\
\hline El mismo, questiones .................... & 1 & 12 \\
\hline Compendium resolutorium ................................ & 1 & 12 \\
\hline Directorium inquisitorum ....................... & 1 & 25 \\
\hline 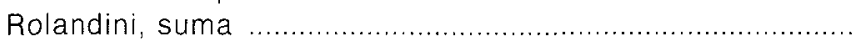 & 1 & 22 \\
\hline 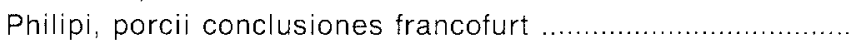 & 1 & 12 \\
\hline 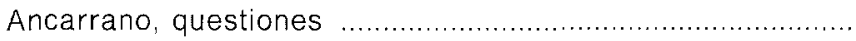 & 1 & 16 \\
\hline Caravita, in vita curie & 1 & 12 \\
\hline Sole, in causis civilis et criminalis & 1 & 10 \\
\hline Mario Munta, capitulo reg. Sicilia ........................ & 1 & 18 \\
\hline 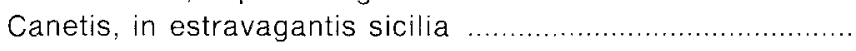 & 1 & 14 \\
\hline 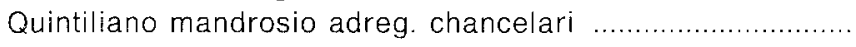 & 1 & 20 \\
\hline Instructorium conciencia, Fr. L. López Salman .................... & 1 & 8 \\
\hline 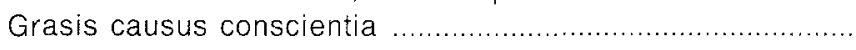 & 1 & 10 \\
\hline 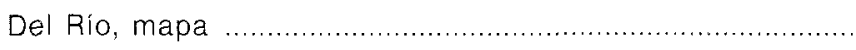 & 1 & 14 \\
\hline Maluis Maleficarum .................. & 1 & 10 \\
\hline Concilio Tridentino de Marcilla ................... & 1 & 9 \\
\hline Repertorium sententia sebastian gormoldo & 2 & 8 \\
\hline 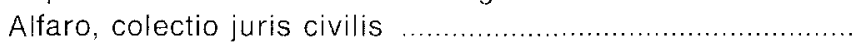 & 1 & 3 \\
\hline 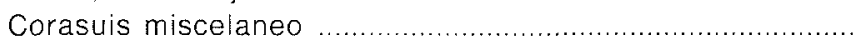 & 1 & 3 \\
\hline El mismo, de Juris arte ......... & 1 & 3 \\
\hline 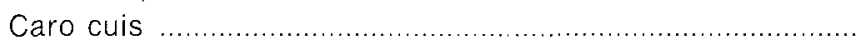 & 1 & 2 \\
\hline Garciarci, patrocinium ..... & 1 & 6 \\
\hline Cancho, anotaciones ....... & 1 & 4 \\
\hline Vaconio, declaratio juris ............... & 1 & 6 \\
\hline Pechio, adregu cancela ...................... & 1 & 3 \\
\hline 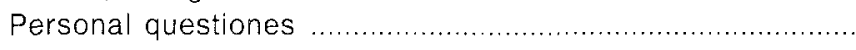 & 1 & 6 \\
\hline Antonio Gómez, in explicatione bulei ...... & 1 & 5 \\
\hline
\end{tabular}


Un regidor madrileño instruido en leyes ...

$\begin{array}{lll}\text { LIBRO O AUTOR } & \text { NUMERO VA.LOR } \\ & \text { CUERPOS } & \text { (EN RS.) }\end{array}$

Doneli epitome, prima parte ….........................................

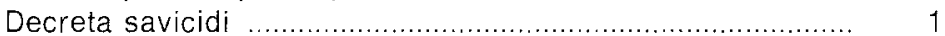

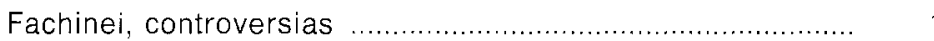

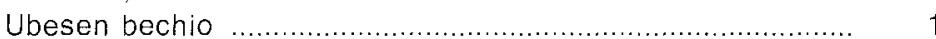

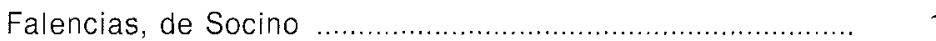

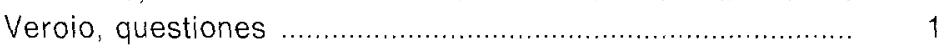

Glosarium juris .......................................................

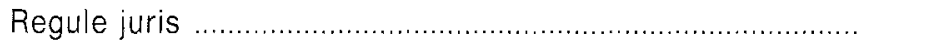

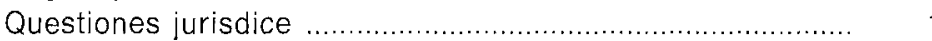

Singularia Doctorum .....................................................

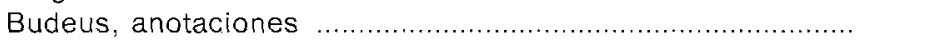

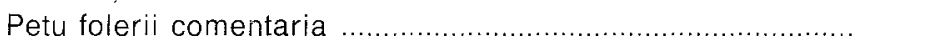

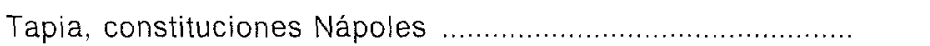

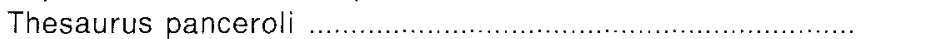

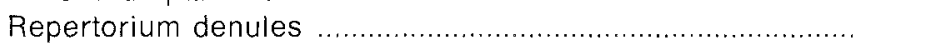

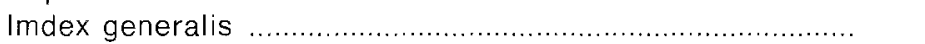

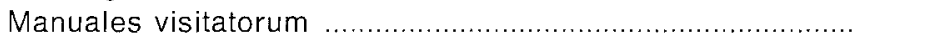

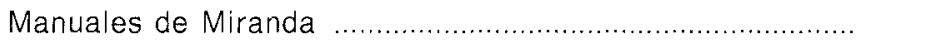

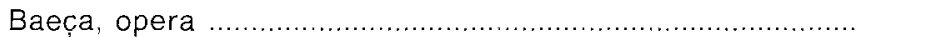

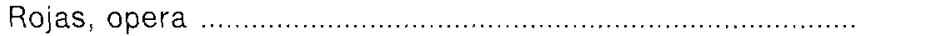

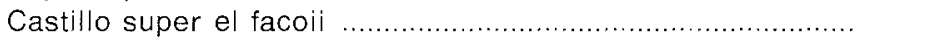

Ordenamiento Real y Leyes de Estilo .................................

Garcia toletano, sucerna rubricarii ....................................

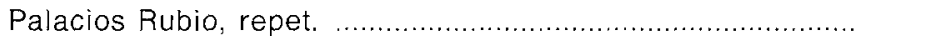

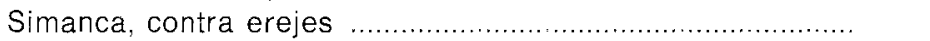

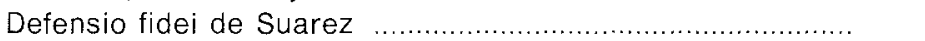

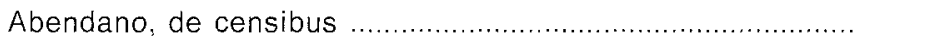

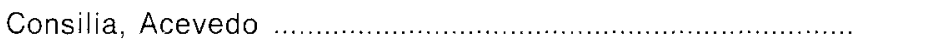

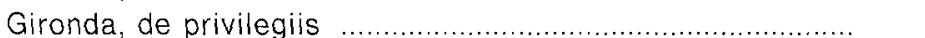

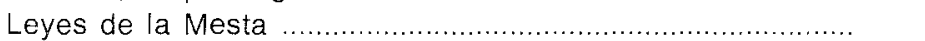

Coaces, de convers pagonores regni .............................. 1

Cortes y premáticas antiguas ..................................... 11

Difiniciones de la orden de Calatrava .............................. $\quad 1 \quad 10$

Montalvo, fuero real ................................................. 12

Silva responsorum ...................................................... $\quad 1 \quad 10$

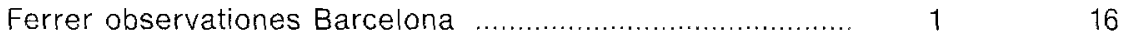

Suma de Sánchez .......................................................... 2

Practica montealegre ..................................................... 1

Rodriguez de exe. y privilegiis ereditores .......................... $2 \quad 2 \quad 14$

Ayora, de partitionibus ................................................... 1

Fueros de Vizcaya ...................................................... 1

Constitutiones del Colegio de Alcalá ................................ 1

Adictiones de la Suma de Ledesma ................................. 1 


\begin{tabular}{|c|c|c|}
\hline LIBRO O AUTOR & $\begin{array}{l}\text { NÚMERO } \\
\text { CUERPOS }\end{array}$ & $\begin{array}{l}\text { VALOR } \\
\text { (EN RS.) }\end{array}$ \\
\hline Molina, de primogeniis & 1 & 20 \\
\hline Navarra, de restituione & 2 & 14 \\
\hline Sahagun, postuma ............. & 1 & 8 \\
\hline 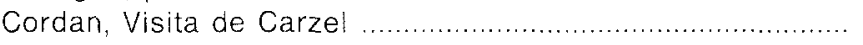 & 1 & 5 \\
\hline Narbona, de apelatione ... & 1 & 5 \\
\hline Mariana, de ponderibus & 1 & 4 \\
\hline 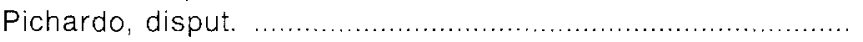 & 1 & 6 \\
\hline Silvero Bernardo, responsa jure patronatus ................ & 1 & 5 \\
\hline 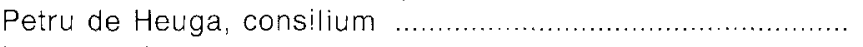 & 1 & 3 \\
\hline 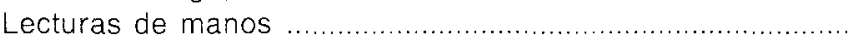 & 3 & 12 \\
\hline 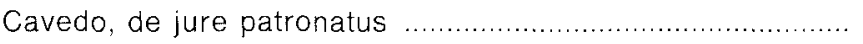 & 1 & 5 \\
\hline Notas ordinarias del Consejo. & 1 & 33 \\
\hline 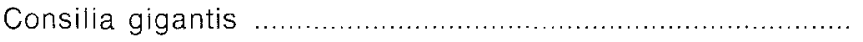 & 1 & 4 \\
\hline Juli Cesariis, bulinjeri de imperat. & 1 & 12 \\
\hline Francisci Balduini, relaxio ........................ & 1 & 5 \\
\hline 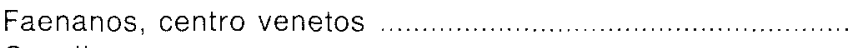 & 1 & 4 \\
\hline 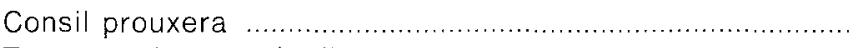 & 1 & 6 \\
\hline 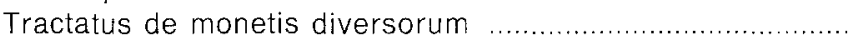 & 1 & 9 \\
\hline 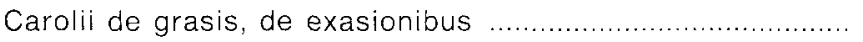 & 1 & 6 \\
\hline 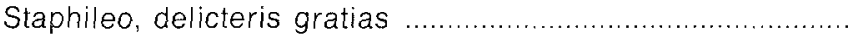 & 1 & 4 \\
\hline Blanco, de compromissis .......................... & 1 & 4 \\
\hline 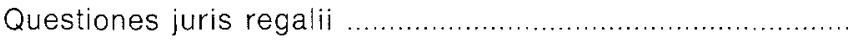 & 1 & 5 \\
\hline 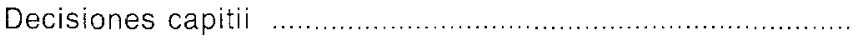 & 1 & 6 \\
\hline 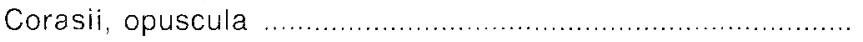 & 1 & 8 \\
\hline Lapiani, madversiones & 1 & 9 \\
\hline Cujaci, opera ....................................... & 4 & 143 \\
\hline 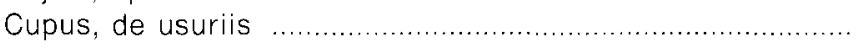 & 1 & 14 \\
\hline 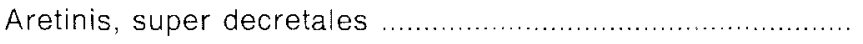 & 1 & 20 \\
\hline 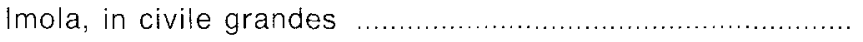 & 4 & 60 \\
\hline 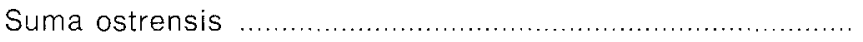 & 1 & 20 \\
\hline Ojeda, de beneficiis ................................ & 1 & 11 \\
\hline Carotio, de locato et conducto ........... & 1 & 16 \\
\hline 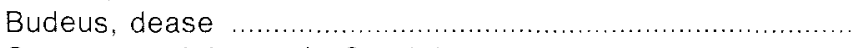 & 1 & 8 \\
\hline 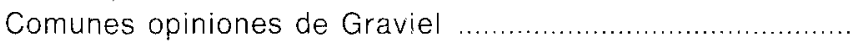 & 1 & 16 \\
\hline 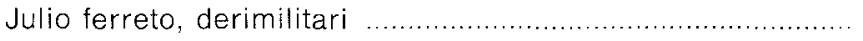 & 1 & 14 \\
\hline Mainerio, de regulis juris ....................... & 1 & 18 \\
\hline Gomesius, in regulas cancellarias ..... & 1 & 8 \\
\hline 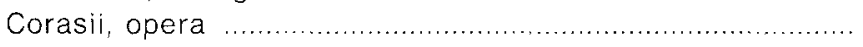 & 2 & 36 \\
\hline 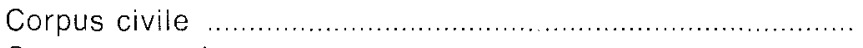 & 6 & 100 \\
\hline Corpus canonicum & 3 & 70 \\
\hline 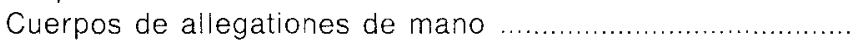 & 23 & 400 \\
\hline 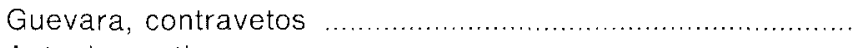 & 1 & 4 \\
\hline 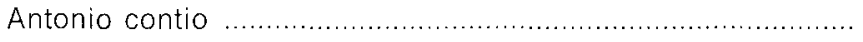 & 1 & 1 \\
\hline Micelanea propia ........ & 1 & 12 \\
\hline
\end{tabular}


Un regidor madrileño instruido en leyes ...

\begin{tabular}{lll}
\hline & NÚMERO & VALOR \\
LIBRO O AUTOR & CUERPOS & (EN FIS.) \\
\hline
\end{tabular}

9. DIVERSOS DE THEOLOGIA Y HUMANIDAD

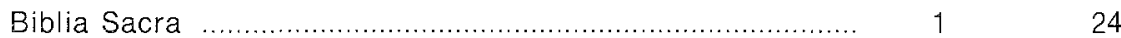

Suma Raimundi .................................................... 1

Sair, clavis rejia ......................................................... 1136

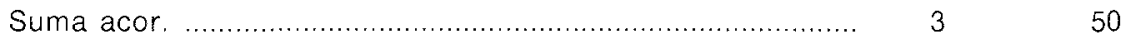

Soto, de justicia et jure ............................................... 16

Frai Luis de Granada ..................................................... 1

Flos Santorum ................................................................ 1

Suma de Rodriguez ................................................ 1

Filosophia moral ........................................................... 1

Historia de Spana de Mariana .......................................... $2 \quad 32$

Ciceronis, opera ........................................................ $4 \quad 66$

Petro Gregorio, de republica ....................................... 1

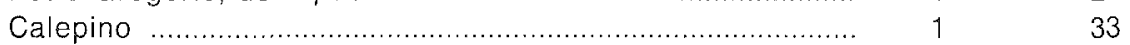

Balles, de sacra filosophia .......................................... 1 .

Casiadoro variarum ....................................................... 110

Amparo de Pobres ...................................................... 1

Oratio, concommento ........................................................ 11

Guvenal y Terencio concommento ................................... 1

Obidio, metamorfoseos et de amore ................................. 1110

Epistolas, del mismo .................................................... 1

Historia rromana ......................................................... $2 \quad 4$

Sanece, opera ........................................................... 2

Anales baronii .............................................................. $12 \quad 400$

Varoni martirolojium ................................................. 1

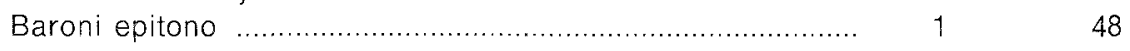

Rosino, de antiquitate ................................................. 1

Historia pontifical .......................................................... $4 \quad 50$

Anales de Aragón ........................................................ $\quad 7 \quad 150$

Justo Lipsio, opera ................................................... $2 \quad 2 \quad 88$

Plinio, natural Historia ................................................... 11

Plutarchi, opera ....................................................... 24

Teatrum vite humane ................................................ 4

Hispania Ylustrata .......................................................... $4 \quad 160$

Carolii Sigonii, opera ................................................. 4

Anales Torneli ....................................................... 1

Anales de Valencia .................................................... 120

Concilia generalia ........................................................ 5

Suma de Toledo ...................................................... 12

Suma silvestrina ........................................................ 11

Historia de Antonio de Herrera ....................................... 114

Ojeda, de vita Christi ................................................... 110 
Don Mauro, historia de Santiago ................................... 1124

Epistola, Plinii ........................................................... 1 .

Bazquez opuscula ..................................................... 1122

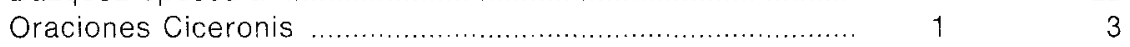

Catulus Tibulus propertuis ........................................... 112

Paramo, de orijine inquisit. ......................................... 1130

Cornelio Tácito, de alamos .......................................... 1

Politica de Villadiego ................................................. 120

Suma de Vega ......................................................... 124

Coletio concilios Hispania ............................................ $1 \quad 30$

Atanassio, de inmunitate ............................................. $1 \quad 30$

Cuchi, institucione mayores ........................................... 1122

Competencias de Milán de Herrera ................................ $1 \quad 6$

Carocio, deposito ....................................................... 11

Guevara, contravenetos ............................................ 11

Relectiones de Vitoria ................................................ 11

Patricio, del reino .......................................................... 11

Cesar Contardo, in lege unicam .................................. 11

Sosa, contravenetos .............................................. 1 .

Decis de Villagut ...................................................... 19

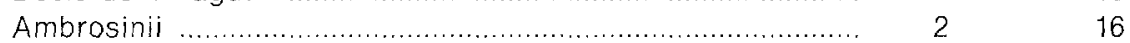

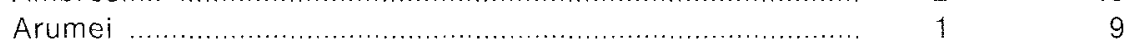

Tratatus de Jure patronatus .......................................... 1 (1

Cosma, de gramatica ascensione .................................. 114

Grasalis .............................................................. $\quad 1 \quad 4$

Farinacio, consejos y decisiones ................................... 2

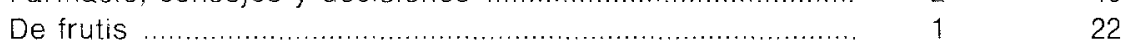

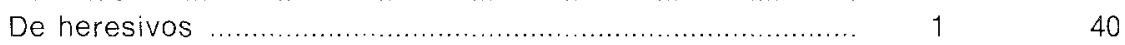

Consilia, Thoma Gramatica ........................................ 1

Omo tomus sp. instituta ............................................... 1122

Decis sese ............................................................ 118

Franco, de apelacionibus ............................................ $1 \quad 30$

Valmaseda y Mendoça, de sumalis .............................. $1 \quad 20$ 